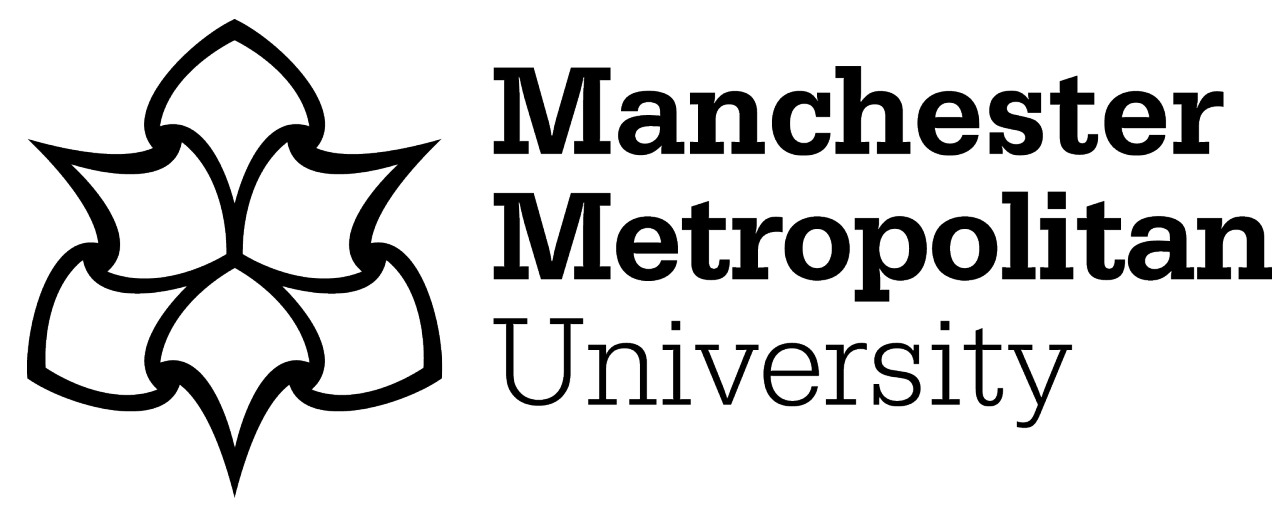

Edmunds, CW, Mukarakate, C, Xu, M, Regmi, YN ORCID logoORCID: https://orcid.org/0000-0001-6588-7683, Hamilton, C, Schaidle, JA, Labbé, N and Chmely, SC (2019) Vapor-Phase Stabilization of Biomass Pyrolysis Vapors Using Mixed-Metal Oxide Catalysts. ACS Sustainable Chemistry and Engineering, 7 (7). pp. 7386-7394. ISSN 2168-0485

Downloaded from: https://e-space.mmu.ac.uk/624772/

Version: Accepted Version

Publisher: American Chemical Society (ACS)

DOI: https://doi.org/10.1021/acssuschemeng.9b00649

Please cite the published version 


\section{Vapor-phase Stabilization of Biomass Pyrolysis Vapors Using Mixed-metal Oxide Catalysts}

Charles W. Edmunds, Calvin Mukarakate, Mengze Xu, Yagya N. Regmi, Choo Hamilton, Joshua A. Schaidle, Nicole Labbé, Stephen Chmely

Submitted date: 26/02/2019 - Posted date: 27/02/2019

Licence: CC BY-NC-ND 4.0

Citation information: Edmunds, Charles W.; Mukarakate, Calvin; Xu, Mengze; Regmi, Yagya N.; Hamilton, Choo; Schaidle, Joshua A.; et al. (2019): Vapor-phase Stabilization of Biomass Pyrolysis Vapors Using Mixed-metal Oxide Catalysts. ChemRxiv. Preprint.

Mixed-metal oxides possess a wide range of tunability and show promise for catalytic stabilization of biomass pyrolysis products. For materials derived from layered double hydroxides, understanding the effect of divalent cation species and divalent/trivalent cation stoichiometric ratio on catalytic behavior is critical to their successful implementation. In this study, four mixed-metal oxide catalysts consisting of $\mathrm{Al}, \mathrm{Zn}$, and $\mathrm{Mg}$ in different stoichiometric ratios were synthesized and tested for ex-situ catalytic fast pyrolysis (CFP) using pine wood as feedstock. The catalytic activity and deactivation behavior of these catalysts were monitored in real-time using a lab-scale pyrolysis reactor and fixed catalyst bed coupled with a molecular beam mass spectrometer (MBMS), and data were analyzed by multivariate statistical approaches. In comparing Mg-and $\mathrm{Zn}$-Al catalyst materials, we demonstrate that the Mg-Al materials possessed greater quantities of basic sites, which we attribute to their higher surface areas, and they produced upgraded pyrolysis vapors which contained less acids and more deoxygenated aromatic hydrocarbons such as toluene and xylene. However, detrimental impacts on carbon yields were realized via decarbonylation and decarboxylation reactions and coke formation. Given that the primary goals of catalytic upgrading of bio-oil are deoxygenation, reduction of acidity, and high carbon yield, these results highlight both promising catalytic effects of mixed-metal oxide materials and opportunities for improvement.

File list (3)

ex-situ pine v00 FINAL SUBMIT.docx (1.19 MiB)

view on ChemRxiv • download file

ex-situ pine v00 FINAL SUBMIT.pdf (875.30 KiB) view on ChemRxiv • download file ex-situ pine SI v03.docx (5.07 MiB) view on ChemRxiv - download file 


\title{
Vapor-phase Stabilization of Biomass Pyrolysis Vapors Using Mixed-metal Oxide Catalysts
}

Charles W. Edmunds ${ }^{l}$, Calvin Mukarakate ${ }^{2}$, Mengze Xu' ${ }^{2}$, Yagya N. Regmi ${ }^{1}$, Choo Hamilton ${ }^{l}$, Joshua A. Schaidle ${ }^{2}$, Nicole Labbél*, Stephen C. Chmely ${ }^{l *}$

1. Center for Renewable Carbon, The University of Tennessee Institute of Agriculture, Knoxville, Tennessee 37996, USA

2. National Renewable Energy Laboratory, 15013 Denver West Parkway, Golden, Colorado 80401 USA

\section{KEYWORDS}

Catalytic fast pyrolysis, vapor-phase upgrading, principal component analysis, layered double hydroxide, mixed-metal oxide

\begin{abstract}
Mixed-metal oxides possess a wide range of tunability and show promise for catalytic stabilization of biomass pyrolysis products. For materials derived from layered double hydroxides, understanding the effect of divalent cation species and divalent/trivalent cation stoichiometric ratio on catalytic behavior is critical to their successful implementation. In this
\end{abstract}


study, four mixed-metal oxide catalysts consisting of $\mathrm{Al}, \mathrm{Zn}$, and $\mathrm{Mg}$ in different stoichiometric ratios were synthesized and tested for $e x$-situ catalytic fast pyrolysis (CFP) using pine wood as feedstock. The catalytic activity and deactivation behavior of these catalysts were monitored in real-time using a lab-scale pyrolysis reactor and fixed catalyst bed coupled with a molecular beam mass spectrometer (MBMS), and data were analyzed by multivariate statistical approaches. In comparing $\mathrm{Mg}$ - and $\mathrm{Zn}-\mathrm{Al}$ catalyst materials, we demonstrate that the $\mathrm{Mg}-\mathrm{Al}$ materials possessed greater quantities of basic sites, which we attribute to their higher surface areas, and they produced upgraded pyrolysis vapors which contained less acids and more deoxygenated aromatic hydrocarbons such as toluene and xylene. However, detrimental impacts on carbon yields were realized via decarbonylation and decarboxylation reactions and coke formation. Given that the primary goals of catalytic upgrading of bio-oil are deoxygenation, reduction of acidity, and high carbon yield, these results highlight both promising catalytic effects of mixedmetal oxide materials and opportunities for improvement.

\section{INTRODUCTION}

Concerns over global greenhouse gas emissions and the finite nature of petroleum motivate research towards sustainable and renewable fuels, chemicals, and bio-based products. Thermochemical conversion of lignocellulosic biomass has been identified as one of several conversion technologies to sustainably produce liquid fuels and chemicals. ${ }^{1}$ During fast pyrolysis, biomass decomposes into pyrolysis vapors, which are condensed to form bio-oil at yields up to $75 \%$ (dry mass basis). ${ }^{2}$ Bio-oil is a complex and heterogeneous mixture of more than 300 compounds including acids, aldehydes, alcohols, ketones, furans, anhydrosugars, phenols, and aromatics. ${ }^{3-4}$ The high oxygen content, high acidity, high water content, and instability of bio-oil mean that it must be upgraded or stabilized to be a viable substitute for liquid petroleum. ${ }^{5}$ 
The application of suitable catalysts to increase bio-oil quality is key for developing thermochemical conversion technologies which can be cost-competitive with petroleum-based fuels and chemicals. ${ }^{6}$

While several investigations exist regarding shape-selective mesoporous acidic catalysts such as the ubiquitous ZSM-5, metal oxide catalysts show great promise for catalytic fast pyrolysis because of their ability to produce bio-oils in relatively high yield that have been substantially deoxygenated and neutralized. For example, Guda and Toghiani reported that sulfate-promoted zirconia afforded bio-oil with lower acidity and higher high-heating value (HHV) when compared to raw bio-oil. ${ }^{7} \mathrm{He}$, Seshan, and co-workers demonstrated that $\mathrm{Na}_{2} \mathrm{CO}_{3} / \mathrm{Al}_{2} \mathrm{O}_{3}$ catalysts could lower the total acid number of bio-oil produced by ex-situ catalytic hydropyrolysis of pine, and addition of Pt metal to the catalyst reduced the number of carbonyl-containing species and more than doubled the HHV. ${ }^{8}$ The same group demonstrated that the interaction between sodium and alumina leads to a different sodium-containing phase that is evidently the active catalytic species, which mediates oxygen-rejection reactions. ${ }^{9}$ Guan and coworkers showed that metal oxides of $2.5 \mathrm{wt} \% \mathrm{Cu}, \mathrm{Fe}$ and $\mathrm{Zn}$ on alumina increased aromatic and aliphatic hydrocarbon yields during ex-situ CFP of $\operatorname{cedar}^{10}$ and sunflower stalks. ${ }^{11}$ Their research also revealed that $\mathrm{Zn}$ containing catalysts were most resistant to coke deposition and that all of the catalysts were easily regenerable by calcination in air. Moreover, the catalysts were resistant to fouling by alkali and alkaline earth metals found in the biomass feedstocks. Mante and coworkers showed that pyrolysis of sugar maple with $\mathrm{TiO}_{2}, \mathrm{CeO}_{\mathrm{x}}-\mathrm{TiO}_{2}$ mixed oxides, and pure $\mathrm{CeO}_{2}, \mathrm{ZrO}_{2}$, and $\mathrm{MgO}$ generated a variety of monofunctional ketones which the authors concluded could be processed downstream to afford hydrocarbon fuels using aldol chemistry. ${ }^{12}$ 
Our group has demonstrated that mixed-metal oxides derived from calcined layered double hydroxide (LDH) precursor materials are promising for bio-oil upgrading and stabilization, ${ }^{13}$ and Navarro's group recently confirmed this reactivity on wheat straw. ${ }^{14}$ Cations in LDHs form organized brucite-like layers separated by interlayers of anions and water molecules. ${ }^{15}$ When the LDH is calcined at temperatures above $400{ }^{\circ} \mathrm{C}$, the resulting material reversibly changes to produce mixed-metal oxides with unique properties such as high porosity, high surface area, and amphoteric catalytic activity. ${ }^{16} \mathrm{~A}$ wide range of anions and cations, and the molar ratios of these, can be readily controlled during synthesis, allowing the ability to tailor materials towards desired catalytic behavior. ${ }^{17}$ Our research on using mixed oxides from LDH precursors to mediate catalytic fast pyrolysis of cellulose demonstrated increased yields of furans in the vapor-phase pyrolysis products and an overall increase of $\mathrm{C}: \mathrm{O}$ ratio in the product vapors. ${ }^{13}$

This study aims to understand the behavior of mixed-metal oxides for the CFP of whole lignocellulosic biomass. The novelty of the research resides in the evaluation of the stability of these catalysts over a range of biomass-to-catalyst ratios $(\mathrm{B} / \mathrm{C})$, and the post-reaction analysis of the catalyst materials to correlate their properties to their performance. We synthesized four mixed-metal oxides consisting of $\mathrm{ZnAl}, \mathrm{Zn}_{2} \mathrm{Al}, \mathrm{MgAl}$, and $\mathrm{Mg}_{2} \mathrm{Al}$ and evaluated them for ex-situ catalytic upgrading of pyrolysis vapors from a pine wood feedstock. In addition, we characterized the basicity and deactivation behavior of the materials. Finally, we discuss how the catalyst composition influences surface properties and catalytic behavior.

\section{EXPERIMENTAL SECTION}

Feedstock Characterization. Southern yellow pine wood feedstock was prepared by milling (40-mesh screen size) prior to compositional analysis, and then milled further (60-mesh screen size) prior to pyrolysis experiments. Cellulose, hemicellulose, lignin, and ash content were 
measured following National Renewable Energy Laboratory procedures. ${ }^{18-19} \mathrm{CHN}$ content was measured with an elemental analyzer (PerkinElmer 2400 series), and oxygen content was calculated by difference. Inorganics composition was measured by inductively coupled plasma optical emission spectrometry (ICP-OES, 7300DV, PerkinElmer, USA) after microwave-assisted acid digestion of $0.5 \mathrm{~g}$ of biomass using a Multiwave 3000 microwave (Anton Paar, VA, USA) following the EPA protocol. ${ }^{20}$

Catalyst Synthesis. We synthesized mixed metal oxide materials labeled $\mathrm{ZnAl}, \mathrm{Zn}_{2} \mathrm{Al}, \mathrm{MgAl}$, and $\mathrm{Mg}_{2} \mathrm{Al}$ from the corresponding $\mathrm{LDH}$ precursors using a method that we reported previously. ${ }^{13}$ An aqueous solution consisting of the appropriate ratios of metal nitrate salts and urea was prepared such that the ratio of urea to nitrate ions was 3:1. The resulting clear colorless solutions were heated to $90{ }^{\circ} \mathrm{C}$ with vigorous stirring for $24 \mathrm{~h}$. The as-formed white precipitate was collected by filtration, washed with water, and dried in ambient air. The dried material was calcined at $500{ }^{\circ} \mathrm{C}$ in static air for $3 \mathrm{~h}$ to obtain the mixed-metal materials, which are denoted by their metal ratios. The materials were sieved to afford particles having a size distribution of 300$500 \mu \mathrm{m}$.

Ex-Situ Catalytic Fast Pyrolysis. We conducted CFP experiments using a horizontal quartz annular flow semi-batch pyrolysis reactor and fixed catalyst bed at $500{ }^{\circ} \mathrm{C}$. The catalyst bed was packed with $1 \mathrm{~g}$ of catalyst and heated to $500{ }^{\circ} \mathrm{C}$ for $30 \mathrm{~min}$ to purge residual moisture prior to pyrolysis experiments. Sequential addition of $50 \mathrm{mg}$ biomass samples held in quartz boats were fed into the reactor every $120 \mathrm{~s}$. The pyrolysis vapors flowed through the catalyst bed and were sampled by molecular beam mass spectrometry (MBMS). Helium was flowed through the reactor $\left(0.7 \mathrm{~Pa} \cdot \mathrm{m}^{3} \mathrm{~s}^{-1}\right)$, and prior to the MBMS inlet, an additional stream of $\mathrm{He}\left(7 \mathrm{~Pa} \cdot \mathrm{m}^{3} \mathrm{~s}^{-1}\right)$ was used to dilute the pyrolysis stream. Argon $\left(0.07 \mathrm{~Pa} \cdot \mathrm{m}^{3} \mathrm{~s}^{-1}\right)$ was used as a tracer to monitor flow 
through the MBMS inlet. The pyrolysis vapors underwent adiabatic expansion through a $250 \mu \mathrm{m}$ orifice into a vacuum chamber held at $13.3 \mathrm{~Pa}$, then the vapors were skimmed to produce a molecular beam before ionization at $22.5 \mathrm{eV}$ to produce positive ions. The ions $(\mathrm{m} / \mathrm{z}=10$ to 450$)$ were detected every second in a quadrupole mass spectrometer. A detailed description of the pyrolysis reactor and MBMS instrumentation was reported previously. ${ }^{21}$ We measured the char yield gravimetrically as $19.3 \pm 0.5 \%$ (wt. basis), which is similar to that reported by others for pyrolysis at $500{ }^{\circ} \mathrm{C}$ of pine wood feedstocks. ${ }^{22-23}$

Catalyst Characterization. Partially and fully deactivated catalyst samples were characterized following pyrolysis experiments. After the appropriate number of $50 \mathrm{mg}$ biomass samples were introduced into the reactor, the catalysts were allowed to cool under He flow $\left(7 \mathrm{~Pa} \cdot \mathrm{m}^{3} \mathrm{~s}^{-1}\right)$, and the catalyst samples were collected and stored in air-tight glass vials.

A Panalytical Empyrean diffractometer with $\mathrm{Cu}$ K- $\alpha 1$ source $(\lambda=1.540598 \AA)$ was used for the powder $\mathrm{x}$-ray diffraction (PXRD) analysis. The beam voltage and current were $45 \mathrm{kV}$ and 40 $\mathrm{mA}$, respectively. The measurements were recorded between $20-80^{\circ}(2 \theta)$, the step size was $0.013^{\circ}(2 \theta)$, and the scan time per step was 29.07 s. Spectral smoothing and background subtraction were performed using the HighScore software package from Panalytical and the reference spectra were obtained from the PDF 4 (2015) database from the International Center for Diffraction Data (ICDD). Thermogravimetric analysis (TGA) was performed using a Perkin Elmer Pyris 1 TGA with approximately $10 \mathrm{mg}$ of sample loaded onto a ceramic pan. The temperature profile consisted of a ramp from $30-900{ }^{\circ} \mathrm{C}$ at $10^{\circ} \mathrm{C} / \mathrm{min}$, followed by a 10 -minute hold at $900{ }^{\circ} \mathrm{C}$.

A Micromeritics Autochem 2920 instrument was used for $\mathrm{CO}_{2}$-TPD measurements. Samples (100 mg) were preheated to $500{ }^{\circ} \mathrm{C}$, held for $120 \mathrm{~min}$, and cooled down to $25^{\circ} \mathrm{C}$ under He flow. 
A mixed flow of $10 \% \mathrm{CO}_{2} / \mathrm{He}$ was dosed over the samples at $25{ }^{\circ} \mathrm{C}$ for $90 \mathrm{~min}$, followed by a flush of $\mathrm{He}$ gas for 45 min to remove physisorbed $\mathrm{CO}_{2}$. Desorption was performed by a temperature ramp at $30{ }^{\circ} \mathrm{C} / \mathrm{min}$ to a final temperature of $500{ }^{\circ} \mathrm{C}$ followed by a $120 \mathrm{~min}$ hold, and the desorbed $\mathrm{CO}_{2}$ was measured by a thermal conductivity detector (TCD). A standard profile of known $\mathrm{CO}_{2}$ volume was used to calibrate TCD signals and quantify the amounts of $\mathrm{CO}_{2}$ desorbed from the samples. Low, medium, and high-temperature Gaussian peaks were deconvoluted from the desorption curves using the Micromeritics Autochem 2920 software. BET surface area was measured with a Micromeritics ASAP 2020 instrument at $-196{ }^{\circ} \mathrm{C}$. Samples were degassed under $\mathrm{N}_{2}$ flow at $350{ }^{\circ} \mathrm{C}$ for $480 \mathrm{~min}$ to remove physisorbed impurities on the surface of the samples before analysis.

Multivariate Statistical Analysis. Multivariate statistical techniques, principal component analysis (PCA) and multivariate curve resolution (MCR), were employed to extract information from the MBMS pyrograms using the statistical software, The Unscrambler ver. 10.4 (Camo software Inc., Woodbridge, NJ). MCR optimized by alternate least squares (ALS) was used to monitor the changes occurring to the vapor product slate as the catalysts were undergoing deactivation by sequential feeding of 50-mg biomass samples (boats) into the horizontal reactor. The MCR-ALS analysis was used to identify initial, intermediate, and primary vapors during CFP of biomass in a manner previously described using zeolite ${ }^{21,24-25}$ and metal oxide ${ }^{22,} 26$ catalysts; detailed discussions of the MCR-ALS is given in those references. Briefly, the MCRALS analysis produces a loadings plot, which contains groups of correlated products (principal components, PCs) and a scores plot, which shows how the grouped products (PCs) from the loadings plot change with catalyst aging (or time on stream or biomass-to-catalyst ratio). The top 100 out of 450 masses with the largest variances were selected for this analysis, resulting in a 
data set with dimensions of 25-30 boats x 100 masses. The MCR-ALS analysis was optimized to give three PCs because increasing the PCs beyond this value did not cause a significant change in the residual error.

\section{RESULTS AND DISCUSSION}

Feedstock Analysis. Southern yellow pine wood was selected as the feedstock for this study due to its abundance in the Southeastern United States, and its potential suitability as a feedstock for production of bioenergy and bioproducts. ${ }^{27}$ The content of cellulose, hemicellulose, and lignin in the biomass was $42.2,19.3$, and $32.9 \%$, respectively (Table S1). The carbon content was $49.7 \%$, the ash content was $0.6 \%$, and the major inorganic elements were $\mathrm{Ca}, \mathrm{Mg}$, and $\mathrm{K}$.

Catalyst Characterization. We characterized all catalyst materials using PXRD, and the results are displayed in Figure S1. These diffraction patterns are in agreement with those of previously reported $\mathrm{Zn}-\mathrm{Al}$ and $\mathrm{Mg}-\mathrm{Al}$ mixed metal oxides which were prepared by calcination in the range of $450-500{ }^{\circ} \mathrm{C} .^{13,28-29}$ The $\mathrm{Mg}-\mathrm{Al}$ and $\mathrm{Zn}-\mathrm{Al}$ materials show broad diffraction peaks indicative of crystalline $\mathrm{MgO}$ and $\mathrm{ZnO}$, respectively. We were unable to detect crystalline alumina $\left(\mathrm{Al}_{2} \mathrm{O}_{3}\right)$ nor spinel-type $\left(\mathrm{MAl}_{2} \mathrm{O}_{4}, M=\mathrm{Mg}\right.$ or $\left.\mathrm{Zn}\right)$ phases in any of the materials.

The BET surface areas of the fresh catalyst materials are shown in Table 1. The surface areas of Mg-Al materials are higher than that of $\mathrm{Zn}-\mathrm{Al}$ materials, and in both $\mathrm{Mg}-\mathrm{Al}$ and $\mathrm{Zn}-\mathrm{Al}$ materials the surface area was higher in materials with higher Al content. Similarly, Palinko et al. reported higher BET surface area in $\mathrm{Mg}$-Al mixed-metal oxides compared to $\mathrm{Zn}$-Al mixed-metal oxide. ${ }^{30}$ An increase in surface area with increasing Al content has been attributed to increased porosity generated by greater $\mathrm{CO}_{2}$ gas evolution during the calcination of the LDH precursor material caused by decomposition of $\mathrm{CO}_{3}{ }^{2-} \cdot 16,29$

Table 1. Surface area and $\mathrm{CO}_{2}-\mathrm{TPD}$ results for mixed-metal oxide catalysts. 
$\begin{array}{llll}\text { Peak } 1 & \text { Peak } 2 & \text { Total } \mathrm{CO}_{2}{ }^{c}\end{array}$

\begin{tabular}{cccccccccc}
$\begin{array}{c}\text { Catalys } \\
\mathrm{t}\end{array}$ & $\begin{array}{c}\mathrm{SA} \\
a\end{array}$ & $\mathrm{~T}^{b}$ & $\mathrm{CO}_{2}{ }^{c}$ & $\mathrm{~T}^{b}$ & $\mathrm{CO}_{2}^{c}$ & $\mathrm{~T}^{b}$ & $\mathrm{CO}_{2}^{c}$ & perg & per $\mathrm{m}^{2 d}$ \\
\hline $\mathrm{ZnAl}$ & 92 & 81 & $14(32 \%)$ & 129 & $16(37 \%)$ & 238 & $14(31 \%)$ & 44 & 0.48 \\
$\mathrm{Zn}_{2} \mathrm{Al}$ & 74 & 77 & $15(31 \%)$ & 120 & $17(35 \%)$ & 209 & $16(33 \%)$ & 48 & 0.65 \\
$\mathrm{MgAl}$ & 195 & 86 & $24(24 \%)$ & 139 & $31(31 \%)$ & 324 & $45(45 \%)$ & 100 & 0.51 \\
$\mathrm{Mg}_{2} \mathrm{Al}$ & 183 & 83 & $12(21 \%)$ & 118 & $18(31 \%)$ & 189 & $27(48 \%)$ & 57 & 0.31
\end{tabular}

$a$ Surface area measured by BET given as $\mathrm{m}^{2} / \mathrm{g}$

$b$ Temperature in ${ }^{\circ} \mathrm{C}$

$c$ Desorbed $\mathrm{CO}_{2}$ given as $\mu \mathrm{mol} / \mathrm{g}$ catalyst. Peak area percentages given are based on total desorbed $\mathrm{CO}_{2}$

$d$ Total $\mathrm{CO}_{2}$ given as $\mu \mathrm{mol} / \mathrm{m}^{2}$ catalyst

We used $\mathrm{CO}_{2}$-TPD to compare basic site density and strength among the different mixed-metal oxides (Table 1 and Figure S2). Three peaks occurring at low, medium, and high temperatures were resolved from the desorption curves. The low temperature peak $\left(\mathrm{T}<120{ }^{\circ} \mathrm{C}\right)$ indicates weakly basic sites (surface $\mathrm{OH}$ groups), the medium temperature peak $\left(120<\mathrm{T}<140{ }^{\circ} \mathrm{C}\right.$ ) corresponds to medium strength basic sites (bridging $\mathrm{O}^{2-}$ sites), and the high temperature peak ( $\mathrm{T}$ $>190{ }^{\circ} \mathrm{C}$ ) indicates strongly basic sites (terminal oxo-type $\mathrm{O}^{2-}$ sites). ${ }^{31-32}$ In addition, the total quantity of desorbed $\mathrm{CO}_{2}$ was calculated by integrating over the entire temperature range.

The total desorbed $\mathrm{CO}_{2}$ and the basic site density (on a mass basis) is greater in the $\mathrm{Mg}-\mathrm{Al}$ materials compared to the $\mathrm{Zn}-\mathrm{Al}$ materials. In addition, the $\mathrm{Mg}-\mathrm{Al}$ materials have a higher percentage of strong basic sites, while the $\mathrm{Zn}-\mathrm{Al}$ materials demonstrated a larger percentage of weak and medium-strength basic sites. The $\mathrm{MgAl}$ sample is unique in that the total desorbed $\mathrm{CO}_{2}$ quantity is greater than the other catalysts, and the high-temperature peak occurs at a higher temperature $\left(324{ }^{\circ} \mathrm{C}\right)$, compared to the other catalysts $\left(189-238^{\circ} \mathrm{C}\right)$. Kagunya and coworkers have noted that the base strength for Zn-containing mixed-metal oxides derived from layered 
double hydroxides is much lower than that of the Mg-containing species, in agreement with the results displayed in Table 1. They attribute these differences in basicity to the differences in divalent cation (Mg vs. $\mathrm{Zn}){ }^{32}$

In general, an increase in $\mathrm{Al}$ content in $\mathrm{Mg}$-Al mixed-metal oxides leads to a decrease in the number of basic sites; however, the remaining sites possess stronger basicity. ${ }^{153-34}$ Di Cosimo et al. reported a similar general trend; however, in mixed-metal oxides with molar $\mathrm{Mg} / \mathrm{Al}$ ratios ranging from 1 to 3 , a localized maximum in basic site density occurred in the sample with $\mathrm{Mg} / \mathrm{Al} \approx 1 .{ }^{16}$ This phenomena of a localized maximum in $\mathrm{Mg}-\mathrm{Al}$ metal oxides in the molar $\mathrm{Mg} / \mathrm{Al}$ ratio range of 1 to 3 is consistent with our observation of greater total desorbed $\mathrm{CO}_{2}$ in the MgAl sample compared to the $\mathrm{Mg}_{2} \mathrm{Al}$ sample. In addition, we observed an increase in the temperature corresponding to the strong basic sites in the $\mathrm{MgAl}$ sample compared to $\mathrm{Mg}_{2} \mathrm{Al}$, which supports the established trend of sites possessing stronger basicity as the ratio of $\mathrm{Al}$ increases.

Catalytic Fast Pyrolysis. The MBMS pyrograms of the pyrolysis vapors from a single $50 \mathrm{mg}$ pine sample, which were treated with the mixed-metal oxide catalysts $(\mathrm{B} / \mathrm{C}=0.1)$ and without a catalyst, are shown in Figure 1. The low B/C for these experiments was selected to probe initial reactivity of the mixed-metal oxide materials. Pyrolysis vapors of pine without mixed-metal oxide catalysts generate complex MBMS pyrograms, but specific high-intensity peaks associated with individual compounds or compound classes can be identified, including acetic acid and hydroxyacetaldehyde $(\mathrm{m} / \mathrm{z}=60)$, carbohydrate fragments $(\mathrm{m} / \mathrm{z}=43,55,57$, and 73$)$, guaiacol $(\mathrm{m} / \mathrm{z}=124)$, methylguaiacol $(\mathrm{m} / \mathrm{z}=138)$, 4-vinylguaiacol $(\mathrm{m} / \mathrm{z}=150)$, eugenol $(\mathrm{m} / \mathrm{z}=164)$, and coniferyl alcohol $(\mathrm{m} / \mathrm{z}=180) .{ }^{35}$ The MBMS pyrograms of non-catalyzed pine are in close agreement to previously reported results for fast pyrolysis of pine wood. ${ }^{21,25}$ When mixed-metal 
oxides were employed, the number of products was reduced, especially for heavy compounds $(\mathrm{m} / \mathrm{z}>115)$. In the catalyzed mass pyrograms, the major peaks observed include low-molecularweight and non-condensable compounds such as water $(\mathrm{m} / \mathrm{z}=18)$, carbon monoxide $(\mathrm{m} / \mathrm{z}=28)$, and carbon dioxide $(\mathrm{m} / \mathrm{z}=44)$, as well as furan $(\mathrm{m} / \mathrm{z}=68)$, and aromatic compounds $(\mathrm{m} / \mathrm{z}=78$, 91, and 106).

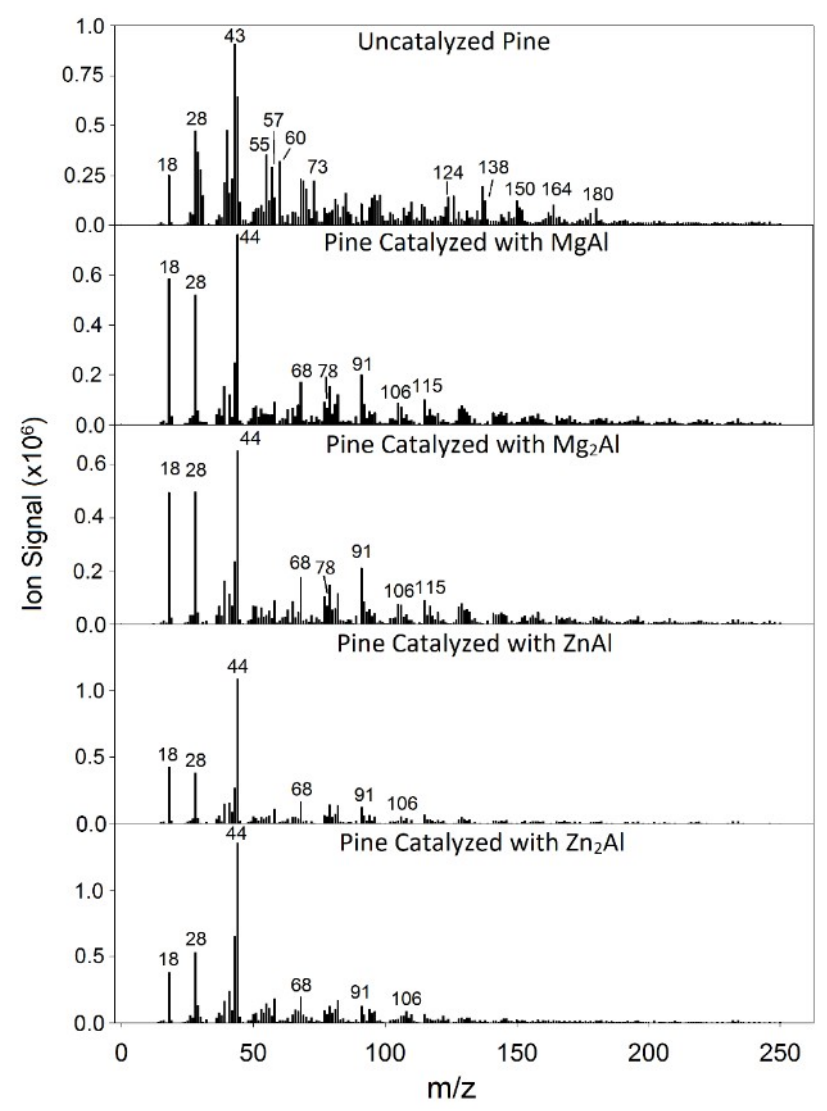

Figure 1. Pyrograms from the horizontal py-MBMS reactor of the non-catalyzed pine feedstock, and pine feedstock catalyzed with $\mathrm{MgAl}, \mathrm{Mg}_{2} \mathrm{Al}, \mathrm{ZnAl}$, and $\mathrm{Zn}_{2} \mathrm{Al}$ mixed-metal oxides with $\mathrm{B} / \mathrm{C}$ $=0.1$.

We used PCA to distinguish changes in the pyrolysis product-slate when different mixed-metal oxides were tested (Fig. 2). The pyrograms of four sequential biomass samples (50 mg) for each catalyst were analyzed. Data from the first run was removed as an outlier, due to initial changes 
to the catalyst, and boats 2-5 were used for the PCA. The PCA scores plot provides a visual representation of the similarities or differences in the vapor-phase products as determined by their placement along the principal component (PC) axes. The loadings plot indicates which major $\mathrm{m} / \mathrm{z}$ peaks are responsible for the variation between samples groups on the scores plot for each respective PC. Since the pyrograms were mean normalized, the obtained results communicate the relative proportions of the vapor products and should not be interpreted in terms of absolute yield.

The PC1 scores plot accounts for $69 \%$ of the variation in the MBMS dataset and shows separation of the non-catalyzed and catalyzed samples mainly driven by low-molecular weight gases, water, $\mathrm{CO}$, and $\mathrm{CO}_{2}$ represented by $\mathrm{m} / \mathrm{z}$ of 18,28 , and 44 , respectively (Fig. 2). Thus, CFP with these mixed-metal oxides affords low-molecular weight gases. Removal of oxygen in the form of $\mathrm{H}_{2} \mathrm{O}, \mathrm{CO}$, or $\mathrm{CO}_{2}$ has been previously reported for CFP with metal oxides catalysts and indicates deoxygenation reactions such as decarbonylation, decarboxylation, ketonization, and dehydration. ${ }^{6,10,13,36}$

Catalyzed reactions result in more furans and aromatic compounds as evidenced by the positive fragments related to furan, methyl furan, toluene, and xylene $(\mathrm{m} / \mathrm{z}=68,82,91$, and $=$ 106, respectively). Pyrolysis vapors from the uncatalyzed reactions are consistent with raw pine. There is a trend of decreasing PC1 score with sequential sample introduction into the pyrolysis reactor, and this is more apparent in the $\mathrm{Zn}-\mathrm{Al}$ catalyzed systems (Fig. 2a). This indicates that the vapor composition is approaching that of the raw pine products because the catalysts are losing activity, and that the $\mathrm{Zn}-\mathrm{Al}$ materials are losing activity more quickly than the $\mathrm{Mg}$-Al materials. 

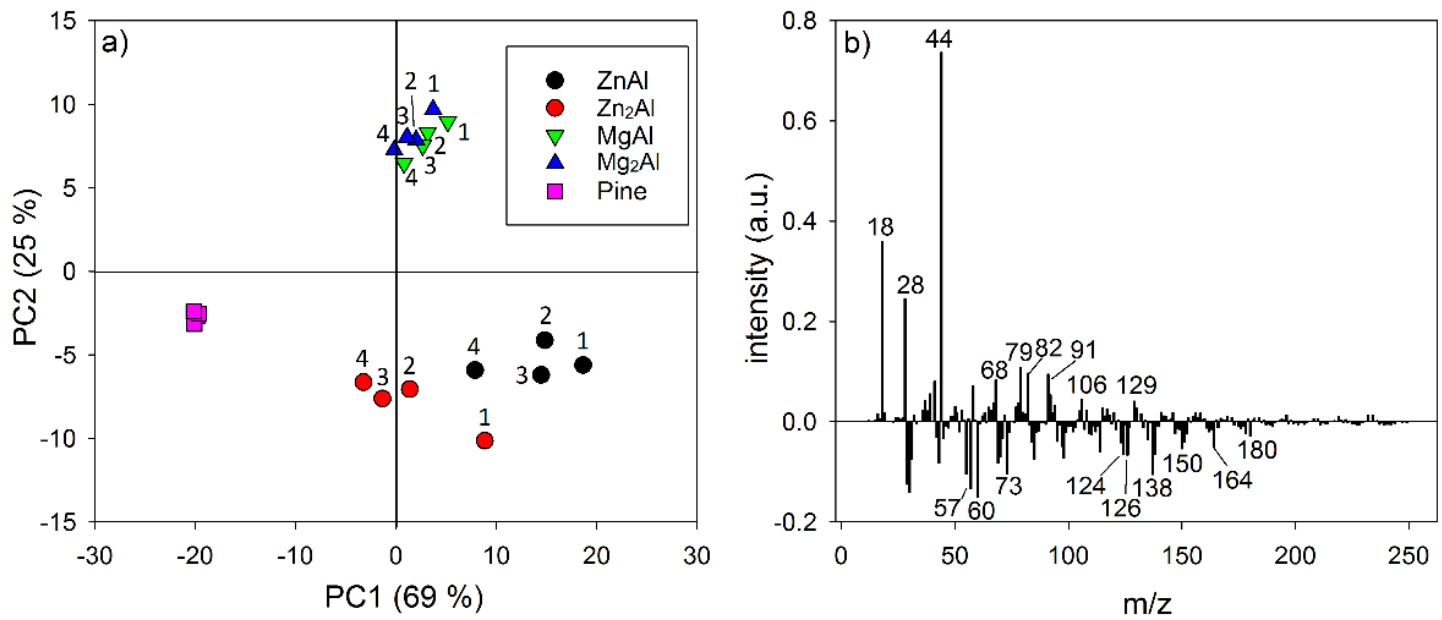

Figure 2. Principal component analysis of MBMS pyrograms from catalyzed and non-catalyzed pine feedstock showing a) the scores plot of PC1 vs. PC2 and b) the loadings plot for PC1. Each point in the scores plot represents one MBMS pyrogram from 4 successive $50 \mathrm{mg}$ biomass samples fed in the horizontal pyrolysis reactor with $\mathrm{B} / \mathrm{C}=0.1-0.25$.

To obtain greater discrimination between the pyrolysis products from the different catalysts, we performed a subsequent PCA excluding the non-catalyzed pine samples (Fig. 3). PC1 shows the separation of CFP products evolved from the $\mathrm{Mg}-\mathrm{Al}$ and $\mathrm{Zn}-\mathrm{Al}$ materials. The $\mathrm{Mg}-\mathrm{Al}$ materials group together on the negative portion of the PC1 axis, indicating that they form similar products. The loadings plot for $\mathrm{PC} 1$ shows that the $\mathrm{Zn}-\mathrm{Al}$ materials produced more $\mathrm{CO}_{2}$ $(\mathrm{m} / \mathrm{z}=44)$, with smaller positive contributions from acetone $(\mathrm{m} / \mathrm{z}=58)$ and methylfuran $(\mathrm{m} / \mathrm{z}=$ 82). Increased $\mathrm{CO}_{2}$ release indicates that $\mathrm{Zn}-\mathrm{Al}$ materials promote decarboxylation reactions, and based on the PC1 loadings, ketonization of acetic acid to form acetone and $\mathrm{CO}_{2}$ is likely occurring. In addition, $\mathrm{PC} 1$ shows that $\mathrm{Mg}-\mathrm{Al}$ catalysts produce more $\mathrm{H}_{2} \mathrm{O}(\mathrm{m} / \mathrm{z}=18)$ and $\mathrm{CO}$ $(\mathrm{m} / \mathrm{z}=28)$ and more non-oxygenated aromatics, toluene and xylene $(\mathrm{m} / \mathrm{z}=91$ and 105 , respectively), compared to $\mathrm{Zn}-\mathrm{Al}$ materials (Fig. 3b). High oxygen content has been shown to reduce bio-oil stability and is a major challenge for fast pyrolysis technology. ${ }^{3-4}$ The greater 
proportion of deoxygenated aromatics afforded by the $\mathrm{Mg}-\mathrm{Al}$ catalysts, compared to $\mathrm{Zn}-\mathrm{Al}$ catalysts, could be beneficial for bio-oil stability and down-stream processing.

PC2 of the scores plot shows rapid deactivation of $\mathrm{Zn}-\mathrm{Al}$ materials as indicated by the trend of more positive PC2 scores values as additional biomass samples are pyrolyzed and the fact that the positive loadings for PC2 show similarities to uncatalyzed pine (Fig. 3a). The PC2 loadings peaks that are common with uncatalyzed pine pyrolysis vapors include carbohydrate fragments $(\mathrm{m} / \mathrm{z}=43$ and 55), guaiacol $(\mathrm{m} / \mathrm{z}=124)$, methylguaiacol $(\mathrm{m} / \mathrm{z}=138)$, 4-vinylguaiacol $(\mathrm{m} / \mathrm{z}=$ 150), and eugenol $(\mathrm{m} / \mathrm{z}=164)$ (Fig. 3c). While we are unable to unambiguously determine the reason for differences in reactivity, we hypothesize that it is related to differences in surface area and acidobasicity among the $\mathrm{Mg}-\mathrm{Al}$ and $\mathrm{Zn}-\mathrm{Al}$ mixed-metal oxides, as is discussed further in subsequent sections. 

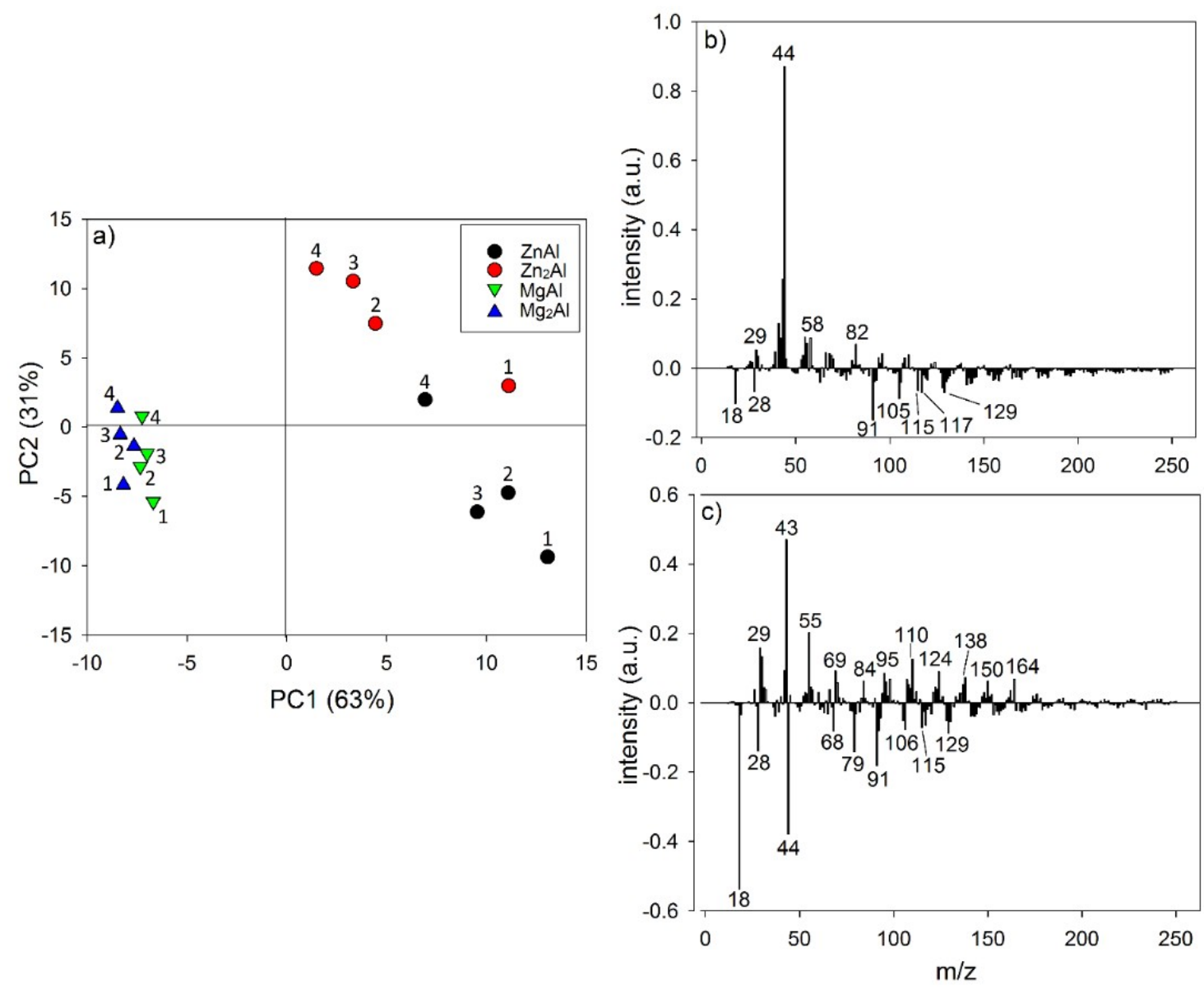

Figure 3. Principal component analysis of MBMS spectra from pine catalyzed by mixed-metal oxides; showing a) the scores plot of PC1 vs. PC2, b) the loadings plot for PC1, and c) the loadings plot for PC2. Each point in the scores plot represents one MBMS spectrum from 4 successive $50 \mathrm{mg}$ biomass samples fed in the horizontal pyrolysis reactor with $\mathrm{B} / \mathrm{C}=0.1-0.25$.

We performed a comparison of peak areas of the major pyrolysis products measured during CFP of pine with mixed-metal oxide catalysts. Percent yields were calculated by summing the following normalized MBMS peaks over $250 \mathrm{mg}$ of biomass (5 boats) for each of the product categories as follows: water $(\mathrm{m} / \mathrm{z}=18), \mathrm{CO}(\mathrm{m} / \mathrm{z}=28), \mathrm{CO}_{2}(\mathrm{~m} / \mathrm{z}=44)$, acetic acid $(\mathrm{m} / \mathrm{z}=60)$, furans $(\mathrm{m} / \mathrm{z}=68,82,96)$, simple phenols $(\mathrm{m} / \mathrm{z}=94,108,122,158)$, methoxyphenols $(\mathrm{m} / \mathrm{z}=124$, 
$137,150,152,164)$, total phenols (simple phenols + methoxyphenols), and aromatics $(\mathrm{m} / \mathrm{z}=78$, 91, 92, 105, and 106) (Fig. 4).

When mixed-metal oxide catalysts were employed, the proportion of acetic acid, methoxyphenols, and total phenols was substantially decreased, while aromatics and light gases $\left(\mathrm{H}_{2} \mathrm{O}, \mathrm{CO}\right.$, and $\left.\mathrm{CO}_{2}\right)$ increased compared to the non-catalyzed control (Fig. 4). The $\mathrm{Zn}-\mathrm{Al}$ materials show greater $\mathrm{CO}_{2}$ production compared to the $\mathrm{Mg}-\mathrm{Al}$ catalysts, indicating that $\mathrm{Zn}-\mathrm{Al}$ materials are more active for decarboxylation reactions. The relative yield of deoxygenated aromatics is the highest when using the Mg-Al materials. These results are supported by the PCA discussed previously (Figs 2 and 3). In addition, there is a reduction in the total ion count when the catalysts are used, which is likely caused by coke deposition on the catalyst surface and a redistribution of the molecular weight of the pyrolysis products.

We are able to make preliminary comparisons between the product selectivity and deactivation behavior between these mixed-metal oxides and more traditional zeolites such as HZSM-5. Zeolite catalysts have been shown to be effective for upgrading lignocellulosic biomass pyrolysis vapors and show high selectivity towards hydrocarbon production. For example, HZSM-5 has been demonstrated to produce olefins, aromatic hydrocarbons, and gases $\left(\mathrm{H}_{2} \mathrm{O}, \mathrm{CO}\right.$, and $\left.\mathrm{CO}_{2}\right)$ when exposed to pine pyrolysis vapors, and similar to the mixed-metal oxide catalysts, a variety of products are formed after initial deactivation occurs. In general, coking and subsequent catalyst fouling are problematic during CFP with zeolites. ${ }^{37}$ We will discuss these and additional conclusions in detail in the subsequent sections. 


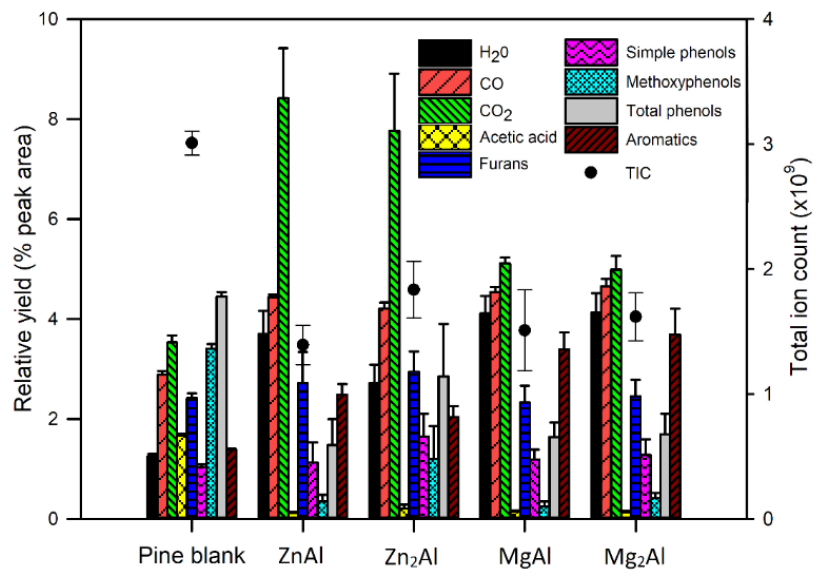

Figure 4. Vapor-phase pyrolysis product yields for pine feedstock without (pine blank) and with $\mathrm{ZnAl}, \mathrm{Zn}_{2} \mathrm{Al}, \mathrm{MgAl}$, and $\mathrm{Mg}_{2} \mathrm{Al}$ mixed-metal oxide catalysts. Vapor products were quantified by integrating and summing the peaks of interest, and then normalizing by the total pyrogram area. The relative yield is plotted on the left y-axis and total ion count is plotted on the right y-axis.

Catalyst Deactivation Behavior. Multivariate curve resolution (MCR) has previously been demonstrated as an effective tool to study catalyst deactivation behavior. ${ }^{21-22,}{ }^{24-25} \mathrm{MCR}$ is a statistical technique in which the "principal components" (PCs) are decomposed from the original MBMS spectra. Each PC represents a uniform mixture of compounds. The concentration of the mixture of compounds over the course of increasing $\mathrm{B} / \mathrm{C}$ is represented by the $\mathrm{PC}$ curve intensity in the component scores plot, while the composition of this mixture is represented by the loadings plot for each respective PC. The MCR plots show how the pyrolysis product slate is changing as $\mathrm{B} / \mathrm{C}$ increases. $\mathrm{B} / \mathrm{C}$ is determined as the addition of successive $50 \mathrm{mg}$ biomass samples which were pyrolyzed and their vapors passed through the $1 \mathrm{~g}$ catalyst bed.

Figure 5 shows the MCR for CFP of pine with $\mathrm{ZnAl}$ and illustrates the compositional evolution of the vapor-phase pyrolysis products as the catalyst undergoes deactivation. The red curve represents the initial products occurring during the initial biomass pulses and includes intense 
peaks for propylene $(\mathrm{m} / \mathrm{z}=41)$, acetone $(\mathrm{m} / \mathrm{z}=58)$, furan $(\mathrm{m} / \mathrm{z}=68)$, methylfuran $(\mathrm{m} / \mathrm{z}=82)$, benzene $(\mathrm{m} / \mathrm{z}=78)$, and toluene $(\mathrm{m} / \mathrm{z}=91)$. The signal at $\mathrm{m} / \mathrm{z} 115$ could be due to indene or naphthol fragmentation. ${ }^{38}$ The intermediate products (black curve) reach a maximum at $\mathrm{B} / \mathrm{C}=$ 0.45 , and the component loadings plot shows that this PC represents partially deoxygenated species, such as acetone $(\mathrm{m} / \mathrm{z}=58)$, furans and phenols including methylfuran $(\mathrm{m} / \mathrm{z}=82)$, phenol $(\mathrm{m} / \mathrm{z}=94)$, dimethyl furan or methylcyclopentenone $(\mathrm{m} / \mathrm{z}=96)$, methylphenol $(\mathrm{m} / \mathrm{z}=108)$, dimethylphenol $(\mathrm{m} / \mathrm{z}=122)$, trimethyl phenol $(\mathrm{m} / \mathrm{z}=136)$, and dimethylbenzofuran $(\mathrm{m} / \mathrm{z}=146)$. The primary vapors (blue curve) appear at a $\mathrm{B} / \mathrm{C}$ higher than 0.4 and they dominate at $\mathrm{B} / \mathrm{C}>1$, indicating that the catalyst was deactivated. The mass spectrum for the blue curve is similar to that for non-catalyzed pine in Figure 1. For comparison, the primary vapors breakthrough immediately for $\mathrm{Zn}_{2} \mathrm{Al}$, which indicates a relative lack of catalytic activity (Fig S3).
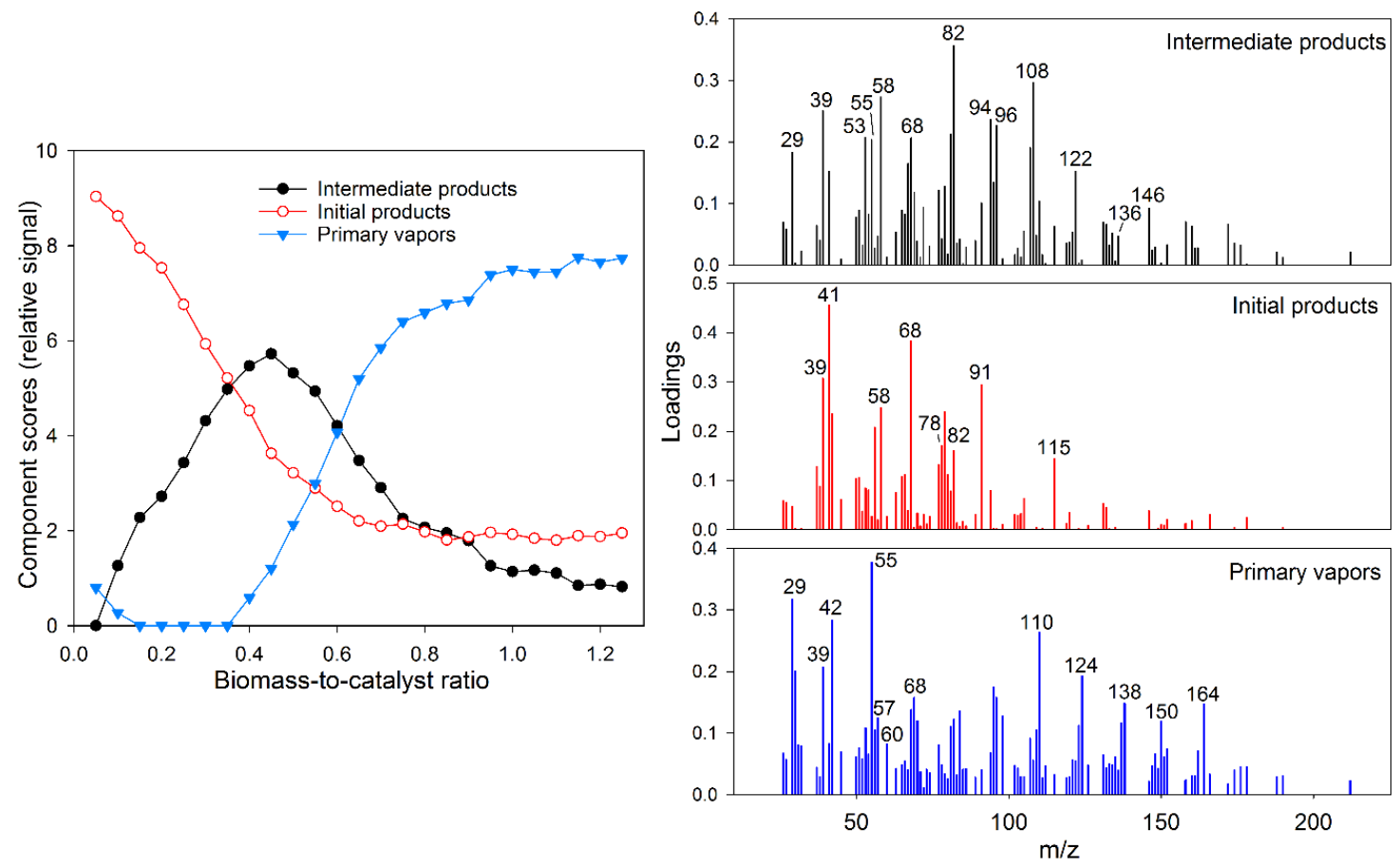
Figure 5. Multivariate curve resolution for ZnAl-catalyzed pine pyrolysis vapor products with respect to increasing $\mathrm{B} / \mathrm{C}$. The principal components scores (left) and accompanying loadings plots (right) are shown.

The vapor-phase pyrolysis product slate for $\mathrm{Mg}_{2} \mathrm{Al}$ and $\mathrm{MgAl}$ are similar (Figs 6 and S4). The initial products show some compounds in common with $\mathrm{ZnAl}$, consisting of propylene $(\mathrm{m} / \mathrm{z}=$ 41), furan $(\mathrm{m} / \mathrm{z}=39,42$, and 68$)$, methylfuran $(\mathrm{m} / \mathrm{z}=82)$, and toluene $(\mathrm{m} / \mathrm{z}=91)$. In addition, the initial products curve for $\mathrm{Mg}$-Al catalysts contained significant contributions from xylene $(\mathrm{m} / \mathrm{z}=106)$. In agreement with both the PCA and comparative product yield analysis, MCR shows that in the initial product vapors, the $\mathrm{Mg}$-Al catalysts produce greater proportions of deoxygenated aromatics such as toluene and xylene. The intermediate products curves for MgAl and $\mathrm{Mg}_{2} \mathrm{Al}$ consisted mostly of dimethyl furan, phenol, and methlyphenols. In the Mg-Al materials, the intermediate products reach a maximum at a higher $\mathrm{B} / \mathrm{C}=0.55$, compared to 0.45 in $\mathrm{ZnAl}$. In addition, the $\mathrm{B} / \mathrm{C}$ in which the primary vapor maximum occurs is highest in $\mathrm{Mg}_{2} \mathrm{Al}$ at 1.2, indicating slightly prolonged activity compared to MgAl. Compared to HZSM-5, these mixed-metal oxides underwent deactivation slightly more quickly. For example, using HZSM-5 under similar conditions, Mukarakate and coworkers reported that the primary vapors breakthrough at a $\mathrm{B} / \mathrm{C}$ of 0.5 , intermediate products peaked at 0.8 , and the initial hydrocarbon products reached a minimum around $\mathrm{B} / \mathrm{C}$ of $1.6 .^{21}$ 

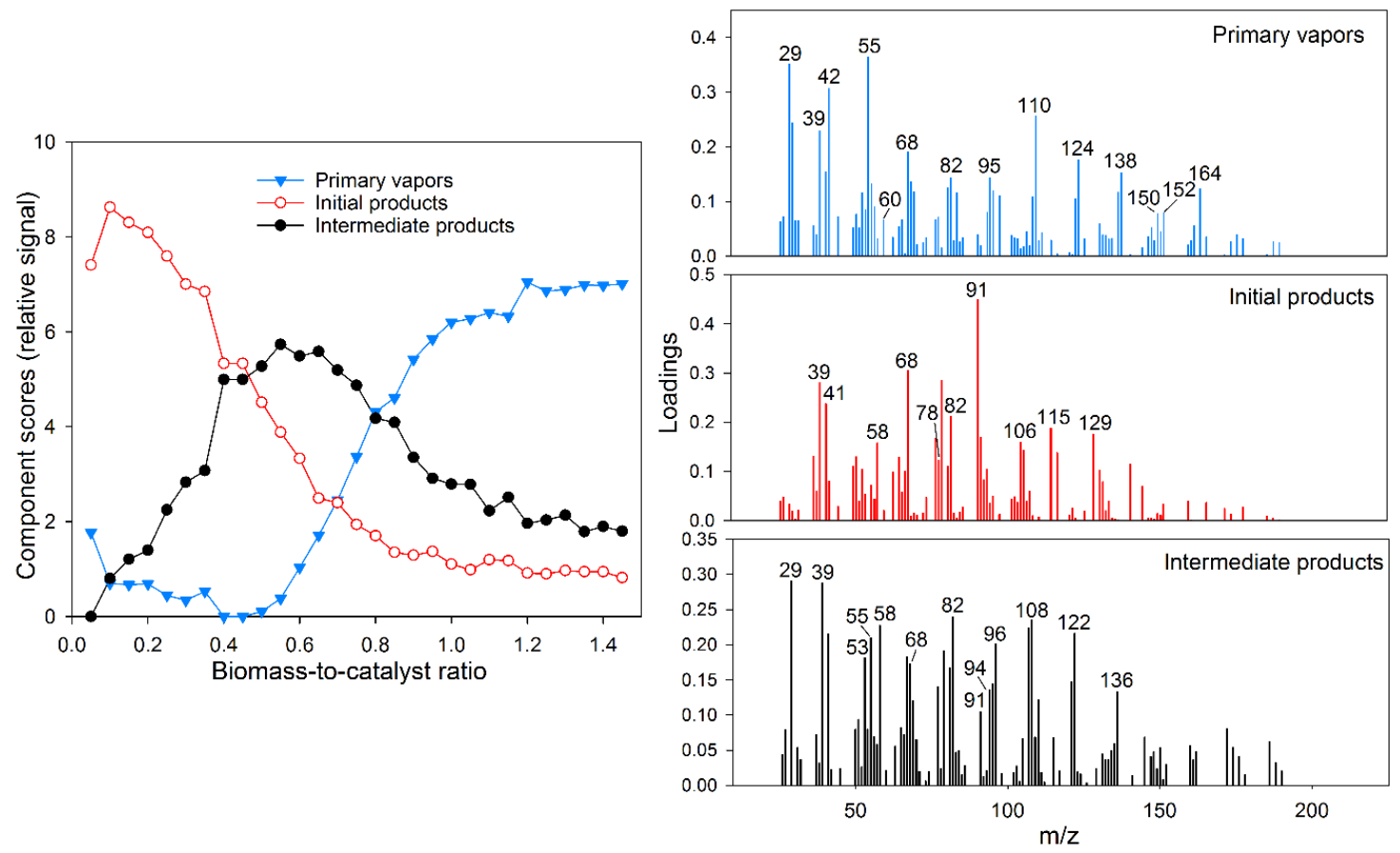

Figure 6. Multivariate curve resolution for $\mathrm{Mg}_{2} \mathrm{Al}$-catalyzed pine pyrolysis vapor products with respect to increasing $\mathrm{B} / \mathrm{C}$. The principal components scores (left) and accompanying loadings plots (right) are shown.

We performed XRD analysis on the deactivated catalyst samples, as shown in Figure S1. Overall, there is no indication of structural changes in the catalysts during or after deactivation. The peak positions and shapes stay relatively constant, suggesting that deactivation was likely a result of coke accumulation physically blocking catalytic active sites and not due to a change in the bulk structure of the materials.

We used TGA to measure the amount of coke accumulated on the catalysts at varying $\mathrm{B} / \mathrm{C}$. The TGA curves show minor weight loss caused by moisture and weakly adsorbed organic compounds at temperatures below $250{ }^{\circ} \mathrm{C}$, while weight loss occurring above $250{ }^{\circ} \mathrm{C}$ was attributed to combustion of coke. ${ }^{38}$ Hence, the weight loss in the range of $250{ }^{\circ} \mathrm{C}$ to $900{ }^{\circ} \mathrm{C}$ was used to determine the amount of coke accumulated on the catalysts (Table 2; Figure S5). 
As expected, there is a positive trend between $\mathrm{B} / \mathrm{C}$ and coke accumulation. $\mathrm{Zn}_{2} \mathrm{Al}$ had less coke accumulation compared to the other catalysts. This may be related to its low surface area, and thus active sites were quickly blocked by coke even at low B/C. The Mg-Al materials showed greater coke accumulation and coke yields in the initial and intermediate phases of activity, which may be related to their higher surface area and greater quantity of active sites (especially in the case of $\mathrm{Mg}_{2} \mathrm{Al}$ ) which supported higher coke loadings before deactivation occurred.

Catalyst deactivation through coke deposition has widely been reported for metal oxides as well as microporous catalysts. ${ }^{6}$ For example, under similar reaction conditions with HZSM-5, Mukarakate et al. reported a coke yield of $15.5 \%$ (wt. coke/wt. biomass fed) after complete deactivation. ${ }^{21}$ For comparison, the mixed-metal oxides tested here (with the exception of $\mathrm{Zn}_{2} \mathrm{Al}$ ) showed similar coke yields after complete deactivation, ranging from 14.2-14.7\%.

Table 2. Coke accumulation at different stages of catalyst deactivation.

\begin{tabular}{|c|c|c|c|c|}
\hline Catalyst & Activity $^{a}$ & $\begin{array}{c}\text { Coke } \\
\text { accumulation }^{b}\end{array}$ & $\begin{array}{l}\text { Coke } \\
\text { yield }^{c}\end{array}$ & $\begin{array}{l}\text { Coke per basic } \\
\text { site }^{d}\end{array}$ \\
\hline & Initial $(0.25)$ & 7.1 & 6.1 & 1.4 \\
\hline \multirow[t]{3}{*}{ ZnAl } & Intermediate $(0.5)$ & 10.3 & 9.2 & 2.1 \\
\hline & Deactivated (1.25) & 15.1 & 14.2 & 3.2 \\
\hline & Initial (0.25) & 4.7 & 4.7 & 0.7 \\
\hline \multirow[t]{3}{*}{$\mathrm{Zn}_{2} \mathrm{Al}$} & Intermediate $(0.5)$ & 5.4 & 5.4 & 0.8 \\
\hline & Deactivated (1.05) & 9.2 & 9.6 & 1.4 \\
\hline & Initial $(0.25)$ & 8.9 & 8.1 & 0.6 \\
\hline \multirow[t]{2}{*}{ MgAl } & Intermediate $(0.7)$ & 14.5 & 14.1 & 1.0 \\
\hline & Deactivated (1.2) & 14.7 & 14.4 & 1.0 \\
\hline \multirow[t]{2}{*}{$\mathrm{Mg}_{2} \mathrm{Al}$} & Initial (0.25) & 9.5 & 7.2 & 1.1 \\
\hline & $\begin{array}{c}\text { Intermediate } \\
(0.75)\end{array}$ & 15.2 & 12.4 & 2.0 \\
\hline
\end{tabular}




\begin{tabular}{l}
\hline Deactivated (1.45) $17.6 \quad 14.7$ \\
\hline$a \mathrm{~B} / \mathrm{C}$ given in parentheses \\
$b$ Given as \% by weight of coke versus catalyst \\
$c$ Given as \% by weight of coke versus total fed biomass \\
$d$ Given as mg coke versus $\mu \mathrm{mol} \mathrm{CO}_{2}$ desorbed
\end{tabular}

Discussion of Catalyst Performance Descriptors. Understanding the effects of the mixed-metal oxide catalyst formulation on catalytic behavior is important to facilitate the design of improved catalysts. We observed that the identity of the divalent cation $\left(\mathrm{Mg}^{2+}\right.$ or $\left.\mathrm{Zn}^{2+}\right)$ affected the surface area and catalytic behavior of the reported materials. This is perhaps unsurprising, given the work of Kaguna and coworkers, who demonstrated that Zn-containing mixed-metal oxide materials displayed overall lower basicity than their Mg-containing counterparts. ${ }^{32}$

We were also able to observe an effect imparted by atom stoichiometries. For instance, in the Mg-Al materials, we observed an increase in basic site density and basic site strength when the divalent/trivalent cation ratio was changed from 2 to 1 (i.e., $\mathrm{Mg}_{2} \mathrm{Al}$ vs. $\mathrm{MgAl}$ ). However, despite these apparent differences in surface properties, $\mathrm{Mg}_{2} \mathrm{Al}$ and $\mathrm{MgAl}$ exhibited similar catalytic activity and deactivation behavior.

There is evidently an interplay between surface basicity (imparted by $\mathrm{MgO}$ and $\mathrm{ZnO}$ ) and Lewis acidity (imparted by $\mathrm{Al}_{2} \mathrm{O}_{3}$ ) among these materials, since the $\mathrm{Mg}-\mathrm{Al}$ catalysts produce higher relative yields of non-oxygenated aromatics including toluene and xylene while remaining active at higher $\mathrm{B} / \mathrm{C}$ compared to $\mathrm{Zn}-\mathrm{Al}$ catalysts. The presence of amorphous alumina in the catalyst materials may explain the formation of non-oxygenated aromatics, which is reactivity typically ascribed to Lewis-acidic materials. Several preparations of mixed-metal oxides from layered double hydroxide precursors have previously shown no evidence for the presence 
crystalline alumina phases,${ }^{32}$ which is a finding similar to our own previous work. ${ }^{13}$ Furthermore, formation of $\gamma$-alumina from amorphous alumina has been shown to occur at $840{ }^{\circ} \mathrm{C},{ }^{39}$ which is well above the synthesis and calcination temperatures we employ here. This apparent acidcatalyzed reactivity highlights an area for improvement among these catalyst materials, since crystalline alumina phases are known to be more acidic (and therefore perhaps more catalytically active for the formation of non-oxygenated aromatics) than amorphous alumina. ${ }^{32,39-40}$

Given that deoxygenation and reduction of acidity of bio-oil are primary goals of catalytic upgrading and result in increased bio-oil stability, the results we report here are promising. However, the mixture of active sites on the surfaces of these mixed-metal oxides is complex and makes their characterization challenging. Our results demonstrate a mixture of weak, moderate, and strong basic sites, which we attribute to the presence of crystalline divalent metal oxides. Moreover, we infer the presence of moderately weak acidic sites which we attribute to the presence of amorphous alumina. Materials having several surface active sites that mediate multiple catalytic transformations simultaneously highlight some of the challenges inherit to designing, scaling, and deploying catalysts for thermochemical biomass conversion. Experiments to rigorously characterize these and other surface sites and their reactivities are ongoing in our laboratories.

\section{ASSOCIATED CONTENT}

The following files are available free of charge:

Compositional analysis of pine feedstock, additional multivariate curve resolutions of catalyst materials, powder x-ray diffractograms of freshly-prepared and after CFP experiments, $\mathrm{CO}_{2}$-TPD curves, and TGA weight loss curves. 


\section{AUTHOR INFORMATION}

\section{Corresponding Authors}

* Email: nlabbe@utk.edu, schmely@utk.edu

\section{Author Contributions}

The manuscript was written through contributions of all authors.

\section{ACKNOWLEDGMENT}

This work was performed under the DOE-funded "Logistics for Enhanced-Attribute Feedstocks" (LEAF) Project, and this material is based upon work supported by the Department of Energy, Office of Energy Efficiency and Renewable Energy (EERE), under Award Number DE-EE0006639. N.L. and S.C.C. also acknowledge support from the USDA National Institute of Food and Agriculture, Hatch Project 1012359. In addition, this work was authored in part by Alliance for Sustainable Energy, LLC, the manager and operator of the National Renewable Energy Laboratory for the U.S. Department of Energy (DOE) under Contract No. DE-AC3608GO28308. Funding provided by U.S. Department of Energy Office of Energy Efficiency and Renewable Energy Bioenergy Technologies Office. The views expressed in the article do not necessarily represent the views of the DOE or the U.S. Government. The U.S. Government retains and the publisher, by accepting the article for publication, acknowledges that the U.S. Government retains a nonexclusive, paid-up, irrevocable, worldwide license to publish or reproduce the published form of this work, or allow others to do so, for U.S. Government purposes.

\section{REFERENCES}


1. Mohan, D.; Pittman, C. U.; Steele, P. H., Pyrolysis of Wood/Biomass for Bio-oil: A Critical Review. Energy Fuels 2006, 20 (3), 848-889. DOI: 10.1021/ef0502397

2. Bridgwater, A. V., Renewable Fuels and Chemicals by Thermal Processing of Biomass. Chem. Eng. J. 2003, 91 (2-3), 87-102. DOI: 10.1016/s1385-8947(02)00142-0

3. Carpenter, D.; Westover, T. L.; Czernik, S.; Jablonski, W., Biomass Feedstocks for Renewable Fuel Production: A Review of the Impacts of Feedstock and Pretreatment on the Yield and Product Distribution of Fast Pyrolysis Bio-Oils and Vapors. Green Chem. 2014, 16 (2), 384-406. DOI: 10.1039/c3gc41631c

4. Ruddy, D. A.; Schaidle, J. A.; Ferrell Iii, J. R.; Wang, J.; Moens, L.; Hensley, J. E., Recent Advances in Heterogeneous Catalysts for Bio-Oil Upgrading via "Ex Situ Catalytic Fast Pyrolysis": Catalyst Development through the Study of Model Compounds. Green Chem. 2014, 16 (2), 454-490. DOI: $10.1039 / \mathrm{c} 3 \mathrm{gc} 41354 \mathrm{c}$

5. Wan, S.; Wang, Y., A Review on Ex Situ Catalytic Fast Pyrolysis of Biomass. Front. Chem. Sci. Eng. 2014, 8 (3), 280-294. DOI: 10.1007/s11705-014-1436-8

6. Liu, C.; Wang, H.; Karim, A. M.; Sun, J.; Wang, Y., Catalytic Fast Pyrolysis of Lignocellulosic Biomass. Chem. Soc. Rev. 2014, 43 (22), 7594-7623. DOI: 10.1039/c3cs60414d

7. Guda, V. K.; Toghiani, H., Catalytic Pyrolysis of Pinewood Using Metal Oxide Catalysts in an Integrated Reactor System. Biofuels 2016, 8 (5), 527-536. DOI: $10.1080 / 17597269.2016 .1231960$ 
8. Nguyen, T. S.; He, S.; Raman, G.; Seshan, K., Catalytic Hydro-Pyrolysis of Lignocellulosic Biomass Over Dual $\mathrm{Na}_{2} \mathrm{CO}_{3} / \mathrm{Al}_{2} \mathrm{O}_{3}$ and $\mathrm{Pt} / \mathrm{Al}_{2} \mathrm{O}_{3}$ Catalysts Using n-Butane at Ambient Pressure. Chem. Eng. J. 2016, 299, 415-419. DOI: 10.1016/j.cej.2016.04.104

9. Nguyen, T. S.; Zabeti, M.; Lefferts, L.; Brem, G.; Seshan, K., Conversion of Lignocellulosic Biomass to Green Fuel Oil over Sodium Based Catalysts. Bioresour. Technol. 2013, 142, 353-360. DOI: 10.1016/j.biortech.2013.05.023

10. Karnjanakom, S.; Guan, G.; Asep, B.; Du, X.; Hao, X.; Yang, J.; Samart, C.; Abudula, A., A Green Method to Increase Yield and Quality of Bio-Oil: Ultrasonic Pretreatment of Biomass and Catalytic Upgrading of Bio-Oil Over Metal $(\mathrm{Cu}, \mathrm{Fe}$ and/ar $\mathrm{Zn}) / \gamma-\mathrm{Al}_{2} \mathrm{O}_{3} . R S C A d v$. 2015, 5 (101), 83494-83503. DOI: 10.1039/c5ra14609g

11. Karnjanakom, S.; Bayu, A.; Xiaoketi, P.; Hao, X.; Kongparakul, S.; Samart, C.; Abudula, A.; Guan, G., Selective Production of Aromatic Hydrocarbons from Catalytic Pyrolysis of Biomass over $\mathrm{Cu}$ or Fe Loaded Mesoporous Rod-Like Alumina. RSC Adv. 2016, 6 (56), 5061850629. DOI: 10.1039/c6ra09431g

12. Mante, O. D.; Rodriguez, J. A.; Senanayake, S. D.; Babu, S. P., Catalytic Conversion of Biomass Pyrolysis Vapors into Hydrocarbon Fuel Precursors. Green Chem. 2015, 17 (4), 23622368. DOI: $10.1039 / \mathrm{c} 4 \mathrm{gc} 02238 \mathrm{f}$

13. Kim, P.; Rials, T. G.; Labbé, N.; Chmely, S. C., Screening of Mixed-Metal Oxide Species for Catalytic Ex Situ Vapor-Phase Deoxygenation of Cellulose by py-GC/MS Coupled with Multivariate Analysis. Energy Fuels 2016, $30 \quad$ (4), 3167-3174. $\quad$ DOI: 10.1021/acs.energyfuels.6b00347 
14. Navarro, R. M.; Guil-Lopez, R.; Fierro, J. L. G.; Mota, N.; Jiménez, S.; Pizarro, P.; Coronado, J. M.; Serrano, D. P., Catalytic fast pyrolysis of biomass over Mg-Al mixed oxides derived from hydrotalcite-like precursors: Influence of $\mathrm{Mg} / \mathrm{Al}$ ratio. J. Anal. Appl. Pyrolysis 2018, 134, 362-370. DOI: 10.1016/j.jaap.2018.07.001

15. Debecker, D. P.; Gaigneaux, E. M.; Busca, G., Exploring, Tuning, and Exploiting the Basicity of Hydrotalcites for Applications in Heterogeneous Catalysis. Chem. Eur. J. 2009, 15 (16), 3920-3935. DOI: 10.1002/chem.200900060

16. Di Cosimo, J. I.; Díez, V. K.; Xu, M.; Iglesia, E.; Apesteguía, C. R., Structure and Surface and Catalytic Properties of Mg-Al Basic Oxides. J. Catal. 1998, 178 (2), 499-510. DOI: 10.1006/jcat.1998.2161

17. Sideris, P. J.; Nielsen, U. G.; Gan, Z.; Grey, C. P., Mg/Al Ordering in Layered Double Hydroxides Revealed by Multinuclear NMR Spectroscopy. Science 2008, 321 (5885), 113-117. DOI: $10.1126 /$ science. 1157581

18. Sluiter, A.; Hames, B.; Ruiz, R.; Scarlata, C.; Sluiter, J.; Templeton, D. Determination of Ash in Biomass; NREL/TP-510-42622; 2008.

19. Sluiter, A.; Hames, B.; Ruiz, R.; Scarlata, C.; Sluiter, J.; Templeton, D. Determination of Structural Carbohydrates and Lignin in Biomass: Laboratory Analytical Procedure (LAP); NREL/TP-510-42618; 2010.

20. Microwave Assisted Acid Digestion of Siliceous and Organically Based Matrices; US EPA Method 3052 rev. 0; 1996. 
21. Mukarakate, C.; Zhang, X.; Stanton, A. R.; Robichaud, D. J.; Ciesielski, P. N.; Malhotra, K.; Donohoe, B. S.; Gjersing, E.; Evans, R. J.; Heroux, D. S.; Richards, R.; Iisa, K.; Nimlos, M. R., Real-Time Monitoring of the Deactivation of HZSM-5 During Upgrading of Pine Pyrolysis Vapors. Green Chem. 2014, 16 (3), 1444-1461. DOI: 10.1039/c3gc42065e

22. Budhi, S.; Mukarakate, C.; Iisa, K.; Pylypenko, S.; Ciesielski, P. N.; Yung, M. M.; Donohoe, B. S.; Katahira, R.; Nimlos, M. R.; Trewyn, B. G., Molybdenum Incorporated Mesoporous Silica Catalyst for Production of Biofuels and Value-Added Chemicals via Catalytic Fast Pyrolysis. Green Chem. 2015, 17 (5), 3035-3046. DOI: 10.1039/c4gc02477j

23. Kim, P.; Weaver, S.; Labbé, N., Effect of Sweeping Gas Flow Rates on TemperatureControlled Multistage Condensation of Pyrolysis Vapors in an Auger Intermediate Pyrolysis System. J. Anal. Appl. Pyrolysis 2016, 118, 325-334. DOI: 10.1016/j.jaap.2016.02.017

24. Jia, L. Y.; Raad, M.; Hamieh, S.; Toufaily, J.; Hamieh, T.; Bettahar, M. M.; Mauviel, G.; Tarrighi, M.; Pinard, L.; Dufour, A., Catalytic Fast Pyrolysis of Biomass: Superior Selectivity of Hierarchical Zeolites to Aromatics. Green Chem. 2017, 19 (22), 5442-5459. DOI: $10.1039 / \mathrm{c} 7 \mathrm{gc} 02309 \mathrm{j}$

25. Mukarakate, C.; Watson, M. J.; ten Dam, J.; Baucherel, X.; Budhi, S.; Yung, M. M.; Ben, H.; Iisa, K.; Baldwin, R. M.; Nimlos, M. R., Upgrading Biomass Pyrolysis Vapors over $\beta$ Zeolites: Role of Silica-to-Alumina Ratio. Green Chem. 2014, 16 (12), 4891-4905. DOI: $10.1039 / \mathrm{c} 4 \mathrm{gc} 01425 \mathrm{a}$

26. Murugappan, K.; Mukarakate, C.; Budhi, S.; Shetty, M.; Nimlos, M. R.; Román-Leshkov, Y., Supported molybdenum oxides as effective catalysts for the catalytic fast pyrolysis of lignocellulosic biomass. Green Chem. 2016, 18 (20), 5548-5557. DOI: 10.1039/c6gc01189f 
27. U.S. Department of Energy. 2016. 2016 Billion-Ton Report: Advancing Domestic Resources for a Thriving Bioeconomy, Volume 1: Economic Availability of Feedstocks. M. H. Langholtz, B. J. Stokes, and L. M. Eaton (Leads), ORNL/TM-2016/160. Oak Ridge National Laboratory, Oak Ridge, TN. 448p. doi: 10.2172/1271651. http://energy.gov/eere/bioenergy/2016billion-ton-report

28. Abelló, S.; Medina, F.; Tichit, D.; Pérez-Ramírez, J.; Groen, J. C.; Sueiras, J. E.; Salagre, P.; Cesteros, Y., Aldol Condensations Over Reconstructed Mg-Al Hydrotalcites: StructureActivity Relationships Related to the Rehydration Method. Chem. Eur. J. 2005, 11 (2), 728-739. DOI: $10.1002 /$ chem.200400409

29. Zhang, Z. B.; Lu, Q.; Ye, X. N.; Li, W. T.; Hu, B.; Dong, C. Q., Selective Analytical Production of 1-Hydroxy-3,6-dioxabicyclo[3.2.1]octan-2-one from Catalytic Fast Pyrolysis of Cellulose with Zinc-Aluminium Layered Double Oxide Catalyst. Bioresources 2015, 10 (4), 8295-8311. DOI:

30. Béres, A.; Pálinkó, I.; Kiricsi, I., Synthesis of Layered Double Hydroxides and Their Reactivities in 1-Butene Isomerization after Calcination. React. Kinet. Catal. Lett. 1996, 59 (1), 47-52. DOI: $10.1007 / \mathrm{bf} 02067991$

31. Pérez-Barrado, E.; Pujol, M. C.; Aguiló, M.; Llorca, J.; Cesteros, Y.; Díaz, F.; Pallarès, J.; Marsal, L. F.; Salagre, P., Influence of Acid-Base Properties of Calcined MgAl and CaAl Layered Double Hydroxides on the Catalytic Glycerol Etherification to Short-chain Polyglycerols. Chem. Eng. J. 2015, 264, 547-556. DOI: 10.1016/j.cej.2014.11.117 
32. Kagunya, W.; Hassan, Z.; Jones, W., Catalytic Properties of Layered Double Hydroxides and Their Calcined Derivatives. Inorg Chem 1996, 35 (21), 5970-5974. DOI: 10.1021/ic960047e

33. Climent, M. J.; Corma, A.; Iborra, S.; Primo, J., Base Catalysis for Fine Chemicals Production: Claisen-Schmidt Condensation on Zeolites and Hydrotalcites for the Production of Chalcones and Flavanones of Pharmaceutical Interest. J. Catal. 1995, 151 (1), 60-66. DOI: 10.1006/jcat.1995.1008

34. Corma, A.; Iborra, S.; Miquel, S.; Primo, J., Catalysts for the Production of Fine Chemicals. J. Catal. 1998, 173 (2), 315-321. DOI: 10.1006/jcat.1997.1930

35. Evans, R. J.; Milne, T. A., Molecular Characterization of the Pyrolysis of Biomass. Energy Fuels 1987, 1 (2), 123-137. DOI: 10.1021/ef00002a001

36. Stefanidis, S. D.; Kalogiannis, K. G.; Iliopoulou, E. F.; Lappas, A. A.; Pilavachi, P. A., InSitu Upgrading of Biomass Pyrolysis Vapors: Catalyst Screening on a Fixed Bed Reactor. Bioresour. Technol. 2011, 102 (17), 8261-8267. DOI: 10.1016/j.biortech.2011.06.032

37. Dickerson, T.; Soria, J., Catalytic Fast Pyrolysis: A Review. Energies 2013, 6 (1), 514538. DOI: $10.3390 / \mathrm{en} 6010514$

38. Mukarakate, C.; McBrayer, J. D.; Evans, T. J.; Budhi, S.; Robichaud, D. J.; Iisa, K.; ten Dam, J.; Watson, M. J.; Baldwin, R. M.; Nimlos, M. R., Catalytic Fast Pyrolysis of Biomass: The Reactions of Water and Aromatic Intermediates Produces Phenols. Green Chem. 2015, 17 (8), 4217-4227. DOI: $10.1039 / \mathrm{c} 5 \mathrm{gc} 00805 \mathrm{k}$ 
39. Abbattista, F.; Delmastro, S.; Gozzelino, G.; Mazza, D.; Vallino, M.; Busca, G.; Lorenzelli, V.; Ramis, G., Surface Characterization of Amorphous Alumina and Its Crystallization Products. J. Catal. 1989, 117 (1), 42-51. DOI: 10.1016/0021-9517(89)90219-4

40. Nortier, P.; Fourre, P.; Saad, A. B. M.; Saur, O.; Lavalley, J. C., Effects of Crystallinity and Morphology on the Surface-Properties of Alumina. Appl Catal 1990, 61 (1), 141-160. DOI: $10.1016 / \mathrm{S} 0166-9834(00) 82140-5$ 


\title{
Vapor-phase Stabilization of Biomass Pyrolysis
}

\section{Vapors Using Mixed-metal Oxide Catalysts}

Charles W. Edmunds ${ }^{1}$, Calvin Mukarakate ${ }^{2}$, Mengze Xu $^{2}$, Yagya N. Regmi ${ }^{1}$, Choo Hamilton ${ }^{1}$, Joshua A. Schaidle ${ }^{2}$, Nicole Labbél* Stephen C. Chmely ${ }^{l *}$

1. Center for Renewable Carbon, The University of Tennessee Institute of Agriculture, Knoxville, Tennessee 37996, USA

2. National Renewable Energy Laboratory, 15013 Denver West Parkway, Golden, Colorado 80401 USA

\section{KEYWORDS}

Catalytic fast pyrolysis, vapor-phase upgrading, principal component analysis, layered double hydroxide, mixed-metal oxide

\begin{abstract}
Mixed-metal oxides possess a wide range of tunability and show promise for catalytic stabilization of biomass pyrolysis products. For materials derived from layered double hydroxides, understanding the effect of divalent cation species and divalent/trivalent cation stoichiometric ratio on catalytic behavior is critical to their successful implementation. In this study, four mixed-metal oxide catalysts consisting of $\mathrm{Al}, \mathrm{Zn}$, and $\mathrm{Mg}$ in different stoichiometric ratios were synthesized
\end{abstract}


and tested for ex-situ catalytic fast pyrolysis (CFP) using pine wood as feedstock. The catalytic activity and deactivation behavior of these catalysts were monitored in real-time using a lab-scale pyrolysis reactor and fixed catalyst bed coupled with a molecular beam mass spectrometer (MBMS), and data were analyzed by multivariate statistical approaches. In comparing Mg- and $\mathrm{Zn}-\mathrm{Al}$ catalyst materials, we demonstrate that the $\mathrm{Mg}-\mathrm{Al}$ materials possessed greater quantities of basic sites, which we attribute to their higher surface areas, and they produced upgraded pyrolysis vapors which contained less acids and more deoxygenated aromatic hydrocarbons such as toluene and xylene. However, detrimental impacts on carbon yields were realized via decarbonylation and decarboxylation reactions and coke formation. Given that the primary goals of catalytic upgrading of bio-oil are deoxygenation, reduction of acidity, and high carbon yield, these results highlight both promising catalytic effects of mixed-metal oxide materials and opportunities for improvement.

\section{INTRODUCTION}

Concerns over global greenhouse gas emissions and the finite nature of petroleum motivate research towards sustainable and renewable fuels, chemicals, and bio-based products. Thermochemical conversion of lignocellulosic biomass has been identified as one of several conversion technologies to sustainably produce liquid fuels and chemicals. ${ }^{1}$ During fast pyrolysis, biomass decomposes into pyrolysis vapors, which are condensed to form bio-oil at yields up to $75 \%$ (dry mass basis). ${ }^{2}$ Bio-oil is a complex and heterogeneous mixture of more than 300 compounds including acids, aldehydes, alcohols, ketones, furans, anhydrosugars, phenols, and aromatics. $^{3-4}$ The high oxygen content, high acidity, high water content, and instability of bio-oil mean that it must be upgraded or stabilized to be a viable substitute for liquid petroleum. ${ }^{5}$ The application of suitable catalysts to increase bio-oil quality is key for developing thermochemical 
conversion technologies which can be cost-competitive with petroleum-based fuels and chemicals. $^{6}$

While several investigations exist regarding shape-selective mesoporous acidic catalysts such as the ubiquitous ZSM-5, metal oxide catalysts show great promise for catalytic fast pyrolysis because of their ability to produce bio-oils in relatively high yield that have been substantially deoxygenated and neutralized. For example, Guda and Toghiani reported that sulfate-promoted zirconia afforded bio-oil with lower acidity and higher high-heating value (HHV) when compared to raw bio-oil. ${ }^{7} \mathrm{He}$, Seshan, and co-workers demonstrated that $\mathrm{Na}_{2} \mathrm{CO}_{3} / \mathrm{Al}_{2} \mathrm{O}_{3}$ catalysts could lower the total acid number of bio-oil produced by ex-situ catalytic hydropyrolysis of pine, and addition of Pt metal to the catalyst reduced the number of carbonyl-containing species and more than doubled the HHV. ${ }^{8}$ The same group demonstrated that the interaction between sodium and alumina leads to a different sodium-containing phase that is evidently the active catalytic species, which mediates oxygen-rejection reactions. ${ }^{9}$ Guan and coworkers showed that metal oxides of $2.5 \mathrm{wt} \%$ $\mathrm{Cu}, \mathrm{Fe}$ and $\mathrm{Zn}$ on alumina increased aromatic and aliphatic hydrocarbon yields during ex-situ CFP of cedar ${ }^{10}$ and sunflower stalks. ${ }^{11}$ Their research also revealed that $\mathrm{Zn}$-containing catalysts were most resistant to coke deposition and that all of the catalysts were easily regenerable by calcination in air. Moreover, the catalysts were resistant to fouling by alkali and alkaline earth metals found in the biomass feedstocks. Mante and coworkers showed that pyrolysis of sugar maple with $\mathrm{TiO}_{2}$, $\mathrm{CeO}_{\mathrm{x}}-\mathrm{TiO}_{2}$ mixed oxides, and pure $\mathrm{CeO}_{2}, \mathrm{ZrO}_{2}$, and $\mathrm{MgO}$ generated a variety of monofunctional ketones which the authors concluded could be processed downstream to afford hydrocarbon fuels using aldol chemistry. ${ }^{12}$

Our group has demonstrated that mixed-metal oxides derived from calcined layered double hydroxide (LDH) precursor materials are promising for bio-oil upgrading and stabilization, ${ }^{13}$ and Navarro's group recently confirmed this reactivity on wheat straw. ${ }^{14}$ Cations in LDHs form 
organized brucite-like layers separated by interlayers of anions and water molecules. ${ }^{15}$ When the LDH is calcined at temperatures above $400^{\circ} \mathrm{C}$, the resulting material reversibly changes to produce mixed-metal oxides with unique properties such as high porosity, high surface area, and amphoteric catalytic activity. ${ }^{16} \mathrm{~A}$ wide range of anions and cations, and the molar ratios of these, can be readily controlled during synthesis, allowing the ability to tailor materials towards desired catalytic behavior. ${ }^{17}$ Our research on using mixed oxides from LDH precursors to mediate catalytic fast pyrolysis of cellulose demonstrated increased yields of furans in the vapor-phase pyrolysis products and an overall increase of $\mathrm{C}: \mathrm{O}$ ratio in the product vapors. ${ }^{13}$

This study aims to understand the behavior of mixed-metal oxides for the CFP of whole lignocellulosic biomass. The novelty of the research resides in the evaluation of the stability of these catalysts over a range of biomass-to-catalyst ratios $(\mathrm{B} / \mathrm{C})$, and the post-reaction analysis of the catalyst materials to correlate their properties to their performance. We synthesized four mixedmetal oxides consisting of $\mathrm{ZnAl}, \mathrm{Zn}_{2} \mathrm{Al}, \mathrm{MgAl}$, and $\mathrm{Mg}_{2} \mathrm{Al}$ and evaluated them for ex-situ catalytic upgrading of pyrolysis vapors from a pine wood feedstock. In addition, we characterized the basicity and deactivation behavior of the materials. Finally, we discuss how the catalyst composition influences surface properties and catalytic behavior.

\section{EXPERIMENTAL SECTION}

Feedstock Characterization. Southern yellow pine wood feedstock was prepared by milling (40-mesh screen size) prior to compositional analysis, and then milled further (60-mesh screen size) prior to pyrolysis experiments. Cellulose, hemicellulose, lignin, and ash content were

measured following National Renewable Energy Laboratory procedures. ${ }^{18-19} \mathrm{CHN}$ content was measured with an elemental analyzer (PerkinElmer 2400 series), and oxygen content was calculated by difference. Inorganics composition was measured by inductively coupled plasma optical emission spectrometry (ICP-OES, 7300DV, PerkinElmer, USA) after microwave-assisted 
acid digestion of $0.5 \mathrm{~g}$ of biomass using a Multiwave 3000 microwave (Anton Paar, VA, USA) following the EPA protocol. ${ }^{20}$

Catalyst Synthesis. We synthesized mixed metal oxide materials labeled $\mathrm{ZnAl}, \mathrm{Zn} 2 \mathrm{Al}, \mathrm{MgAl}$, and $\mathrm{Mg}_{2} \mathrm{Al}$ from the corresponding $\mathrm{LDH}$ precursors using a method that we reported previously. ${ }^{13}$ An aqueous solution consisting of the appropriate ratios of metal nitrate salts and urea was prepared such that the ratio of urea to nitrate ions was $3: 1$. The resulting clear colorless solutions were heated to $90^{\circ} \mathrm{C}$ with vigorous stirring for $24 \mathrm{~h}$. The as-formed white precipitate was collected by filtration, washed with water, and dried in ambient air. The dried material was calcined at 500 ${ }^{\circ} \mathrm{C}$ in static air for $3 \mathrm{~h}$ to obtain the mixed-metal materials, which are denoted by their metal ratios. The materials were sieved to afford particles having a size distribution of 300-500 $\mu \mathrm{m}$.

Ex-Situ Catalytic Fast Pyrolysis. We conducted CFP experiments using a horizontal quartz annular flow semi-batch pyrolysis reactor and fixed catalyst bed at $500{ }^{\circ} \mathrm{C}$. The catalyst bed was packed with $1 \mathrm{~g}$ of catalyst and heated to $500{ }^{\circ} \mathrm{C}$ for $30 \mathrm{~min}$ to purge residual moisture prior to pyrolysis experiments. Sequential addition of $50 \mathrm{mg}$ biomass samples held in quartz boats were fed into the reactor every $120 \mathrm{~s}$. The pyrolysis vapors flowed through the catalyst bed and were sampled by molecular beam mass spectrometry (MBMS). Helium was flowed through the reactor $\left(0.7 \mathrm{~Pa} \cdot \mathrm{m}^{3} \mathrm{~s}^{-1}\right)$, and prior to the MBMS inlet, an additional stream of $\mathrm{He}\left(7 \mathrm{~Pa} \cdot \mathrm{m}^{3} \mathrm{~s}^{-1}\right)$ was used to dilute the pyrolysis stream. Argon $\left(0.07 \mathrm{~Pa} \cdot \mathrm{m}^{3} \mathrm{~s}^{-1}\right)$ was used as a tracer to monitor flow through the MBMS inlet. The pyrolysis vapors underwent adiabatic expansion through a $250 \mu \mathrm{m}$ orifice into a vacuum chamber held at $13.3 \mathrm{~Pa}$, then the vapors were skimmed to produce a molecular beam before ionization at $22.5 \mathrm{eV}$ to produce positive ions. The ions $(\mathrm{m} / \mathrm{z}=10$ to 450$)$ were detected every second in a quadrupole mass spectrometer. A detailed description of the pyrolysis reactor and MBMS instrumentation was reported previously. ${ }^{21}$ We measured the char yield 
gravimetrically as $19.3 \pm 0.5 \%$ (wt. basis), which is similar to that reported by others for pyrolysis at $500{ }^{\circ} \mathrm{C}$ of pine wood feedstocks..$^{22-23}$

Catalyst Characterization. Partially and fully deactivated catalyst samples were characterized following pyrolysis experiments. After the appropriate number of $50 \mathrm{mg}$ biomass samples were introduced into the reactor, the catalysts were allowed to cool under He flow $\left(7 \mathrm{~Pa} \cdot \mathrm{m}^{3} \mathrm{~s}^{-1}\right)$, and the catalyst samples were collected and stored in air-tight glass vials.

A Panalytical Empyrean diffractometer with $\mathrm{Cu}$ K- $\alpha 1$ source $(\lambda=1.540598 \AA)$ was used for the powder x-ray diffraction (PXRD) analysis. The beam voltage and current were $45 \mathrm{kV}$ and $40 \mathrm{~mA}$, respectively. The measurements were recorded between $20-80^{\circ}(2 \theta)$, the step size was $0.013^{\circ}(2 \theta)$, and the scan time per step was 29.07 s. Spectral smoothing and background subtraction were performed using the HighScore software package from Panalytical and the reference spectra were obtained from the PDF 4 (2015) database from the International Center for Diffraction Data (ICDD). Thermogravimetric analysis (TGA) was performed using a Perkin Elmer Pyris 1 TGA with approximately $10 \mathrm{mg}$ of sample loaded onto a ceramic pan. The temperature profile consisted of a ramp from $30-900{ }^{\circ} \mathrm{C}$ at $10^{\circ} \mathrm{C} / \mathrm{min}$, followed by a 10 -minute hold at $900{ }^{\circ} \mathrm{C}$.

A Micromeritics Autochem 2920 instrument was used for $\mathrm{CO}_{2}$-TPD measurements. Samples (100 mg) were preheated to $500{ }^{\circ} \mathrm{C}$, held for $120 \mathrm{~min}$, and cooled down to $25^{\circ} \mathrm{C}$ under He flow. A mixed flow of $10 \% \mathrm{CO}_{2} / \mathrm{He}$ was dosed over the samples at $25^{\circ} \mathrm{C}$ for $90 \mathrm{~min}$, followed by a flush of He gas for 45 min to remove physisorbed $\mathrm{CO}_{2}$. Desorption was performed by a temperature ramp at $30{ }^{\circ} \mathrm{C} / \mathrm{min}$ to a final temperature of $500{ }^{\circ} \mathrm{C}$ followed by a $120 \mathrm{~min}$ hold, and the desorbed $\mathrm{CO}_{2}$ was measured by a thermal conductivity detector (TCD). A standard profile of known $\mathrm{CO}_{2}$ volume was used to calibrate TCD signals and quantify the amounts of $\mathrm{CO}_{2}$ desorbed from the samples. Low, medium, and high-temperature Gaussian peaks were deconvoluted from the desorption curves using the Micromeritics Autochem 2920 software. BET surface area was 
measured with a Micromeritics ASAP 2020 instrument at $-196^{\circ} \mathrm{C}$. Samples were degassed under $\mathrm{N}_{2}$ flow at $350{ }^{\circ} \mathrm{C}$ for 480 min to remove physisorbed impurities on the surface of the samples before analysis.

Multivariate Statistical Analysis. Multivariate statistical techniques, principal component analysis (PCA) and multivariate curve resolution (MCR), were employed to extract information from the MBMS pyrograms using the statistical software, The Unscrambler ver. 10.4 (Camo software Inc., Woodbridge, NJ). MCR optimized by alternate least squares (ALS) was used to monitor the changes occurring to the vapor product slate as the catalysts were undergoing deactivation by sequential feeding of 50-mg biomass samples (boats) into the horizontal reactor. The MCR-ALS analysis was used to identify initial, intermediate, and primary vapors during CFP of biomass in a manner previously described using zeolite ${ }^{21,24-25}$ and metal oxide 22,26 catalysts; detailed discussions of the MCR-ALS is given in those references. Briefly, the MCR-ALS analysis produces a loadings plot, which contains groups of correlated products (principal components, PCs) and a scores plot, which shows how the grouped products (PCs) from the loadings plot change with catalyst aging (or time on stream or biomass-to-catalyst ratio). The top 100 out of 450 masses with the largest variances were selected for this analysis, resulting in a data set with dimensions of 25-30 boats x 100 masses. The MCR-ALS analysis was optimized to give three PCs because increasing the PCs beyond this value did not cause a significant change in the residual error.

\section{RESULTS AND DISCUSSION}

Feedstock Analysis. Southern yellow pine wood was selected as the feedstock for this study due to its abundance in the Southeastern United States, and its potential suitability as a feedstock for production of bioenergy and bioproducts. ${ }^{27}$ The content of cellulose, hemicellulose, and lignin in the biomass was $42.2,19.3$, and $32.9 \%$, respectively (Table S1). The carbon content was $49.7 \%$, the ash content was $0.6 \%$, and the major inorganic elements were $\mathrm{Ca}, \mathrm{Mg}$, and $\mathrm{K}$. 
Catalyst Characterization. We characterized all catalyst materials using PXRD, and the results are displayed in Figure S1. These diffraction patterns are in agreement with those of previously reported $\mathrm{Zn}-\mathrm{Al}$ and $\mathrm{Mg}-\mathrm{Al}$ mixed metal oxides which were prepared by calcination in the range of 450-500 ${ }^{\circ} \mathrm{C} .{ }^{13,28-29}$ The $\mathrm{Mg}-\mathrm{Al}$ and $\mathrm{Zn}-\mathrm{Al}$ materials show broad diffraction peaks indicative of crystalline $\mathrm{MgO}$ and $\mathrm{ZnO}$, respectively. We were unable to detect crystalline alumina $\left(\mathrm{Al}_{2} \mathrm{O}_{3}\right)$ nor spinel-type $\left(\mathrm{MAl}_{2} \mathrm{O}_{4}, M=\mathrm{Mg}\right.$ or $\left.\mathrm{Zn}\right)$ phases in any of the materials.

The BET surface areas of the fresh catalyst materials are shown in Table 1. The surface areas of $\mathrm{Mg}-\mathrm{Al}$ materials are higher than that of $\mathrm{Zn}-\mathrm{Al}$ materials, and in both $\mathrm{Mg}-\mathrm{Al}$ and $\mathrm{Zn}-\mathrm{Al}$ materials the surface area was higher in materials with higher Al content. Similarly, Palinko et al. reported higher BET surface area in Mg-Al mixed-metal oxides compared to $\mathrm{Zn}$-Al mixed-metal oxide. ${ }^{30}$ An increase in surface area with increasing Al content has been attributed to increased porosity generated by greater $\mathrm{CO}_{2}$ gas evolution during the calcination of the LDH precursor material caused by decomposition of $\mathrm{CO}_{3}{ }^{2-} \cdot{ }^{16,29}$

Table 1. Surface area and $\mathrm{CO}_{2}$-TPD results for mixed-metal oxide catalysts.

\begin{tabular}{|c|c|c|c|c|c|c|c|c|c|}
\hline \multirow[b]{2}{*}{ Catalyst } & \multirow[b]{2}{*}{$\mathrm{SA}$} & \multicolumn{2}{|r|}{ Peak 1} & \multicolumn{2}{|c|}{ Peak 2} & \multicolumn{2}{|c|}{ Peak 3} & \multicolumn{2}{|c|}{ Total $\mathrm{CO}_{2}{ }^{c}$} \\
\hline & & $\mathrm{T}^{b}$ & $\mathrm{CO}_{2}{ }^{c}$ & $\mathrm{~T}^{b}$ & $\mathrm{CO}_{2}{ }^{c}$ & $\mathrm{~T}^{b}$ & $\mathrm{CO}_{2}{ }^{c}$ & per $g$ & per $\mathrm{m}^{2 d}$ \\
\hline $\mathrm{ZnAl}$ & 92 & 81 & $14(32 \%)$ & 129 & $16(37 \%)$ & 238 & $14(31 \%)$ & 44 & 0.48 \\
\hline $\mathrm{Zn}_{2} \mathrm{Al}$ & 74 & 77 & $15(31 \%)$ & 120 & $17(35 \%)$ & 209 & $16(33 \%)$ & 48 & 0.65 \\
\hline $\mathrm{MgAl}$ & 195 & 86 & $24(24 \%)$ & 139 & $31(31 \%)$ & 324 & $45(45 \%)$ & 100 & 0.51 \\
\hline $\mathrm{Mg}_{2} \mathrm{Al}$ & 183 & 83 & $12(21 \%)$ & 118 & $18(31 \%)$ & 189 & $27(48 \%)$ & 57 & 0.31 \\
\hline
\end{tabular}

$a$ Surface area measured by BET given as $\mathrm{m}^{2} / \mathrm{g}$

$b$ Temperature in ${ }^{\circ} \mathrm{C}$

$c$ Desorbed $\mathrm{CO}_{2}$ given as $\mu \mathrm{mol} / \mathrm{g}$ catalyst. Peak area percentages given are based on total desorbed $\mathrm{CO}_{2}$

$d$ Total $\mathrm{CO}_{2}$ given as $\mu \mathrm{mol} / \mathrm{m}^{2}$ catalyst 
We used $\mathrm{CO}_{2}$-TPD to compare basic site density and strength among the different mixed-metal oxides (Table 1 and Figure S2). Three peaks occurring at low, medium, and high temperatures were resolved from the desorption curves. The low temperature peak $\left(\mathrm{T}<120^{\circ} \mathrm{C}\right)$ indicates weakly basic sites (surface $\mathrm{OH}$ groups), the medium temperature peak $\left(120<\mathrm{T}<140{ }^{\circ} \mathrm{C}\right)$ corresponds to medium strength basic sites (bridging $\mathrm{O}^{2-}$ sites), and the high temperature peak $\left(\mathrm{T}>190{ }^{\circ} \mathrm{C}\right)$ indicates strongly basic sites (terminal oxo-type $\mathrm{O}^{2-}$ sites). ${ }^{31-32}$ In addition, the total quantity of desorbed $\mathrm{CO}_{2}$ was calculated by integrating over the entire temperature range.

The total desorbed $\mathrm{CO}_{2}$ and the basic site density (on a mass basis) is greater in the $\mathrm{Mg}-\mathrm{Al}$ materials compared to the $\mathrm{Zn}$-Al materials. In addition, the Mg-Al materials have a higher percentage of strong basic sites, while the $\mathrm{Zn}$-Al materials demonstrated a larger percentage of weak and medium-strength basic sites. The $\mathrm{MgAl}$ sample is unique in that the total desorbed $\mathrm{CO}_{2}$ quantity is greater than the other catalysts, and the high-temperature peak occurs at a higher temperature $\left(324{ }^{\circ} \mathrm{C}\right)$, compared to the other catalysts $\left(189-238{ }^{\circ} \mathrm{C}\right)$. Kagunya and coworkers have noted that the base strength for $\mathrm{Zn}$-containing mixed-metal oxides derived from layered double hydroxides is much lower than that of the Mg-containing species, in agreement with the results displayed in Table 1. They attribute these differences in basicity to the differences in divalent cation (Mg vs. $\mathrm{Zn}){ }^{32}$

In general, an increase in $\mathrm{Al}$ content in $\mathrm{Mg}$ - $\mathrm{Al}$ mixed-metal oxides leads to a decrease in the number of basic sites; however, the remaining sites possess stronger basicity. ${ }^{15,33-34}$ Di Cosimo et al. reported a similar general trend; however, in mixed-metal oxides with molar $\mathrm{Mg} / \mathrm{Al}$ ratios ranging from 1 to 3, a localized maximum in basic site density occurred in the sample with $\mathrm{Mg} / \mathrm{Al}$ $\approx 1 .{ }^{16}$ This phenomena of a localized maximum in $\mathrm{Mg}-\mathrm{Al}$ metal oxides in the molar $\mathrm{Mg} / \mathrm{Al}$ ratio range of 1 to 3 is consistent with our observation of greater total desorbed $\mathrm{CO}_{2}$ in the $\mathrm{MgAl}$ sample compared to the $\mathrm{Mg}_{2} \mathrm{Al}$ sample. In addition, we observed an increase in the temperature 
corresponding to the strong basic sites in the $\mathrm{MgAl}$ sample compared to $\mathrm{Mg}_{2} \mathrm{Al}$, which supports the established trend of sites possessing stronger basicity as the ratio of $\mathrm{Al}$ increases.

Catalytic Fast Pyrolysis. The MBMS pyrograms of the pyrolysis vapors from a single $50 \mathrm{mg}$ pine sample, which were treated with the mixed-metal oxide catalysts $(\mathrm{B} / \mathrm{C}=0.1)$ and without a catalyst, are shown in Figure 1. The low B/C for these experiments was selected to probe initial reactivity of the mixed-metal oxide materials. Pyrolysis vapors of pine without mixed-metal oxide catalysts generate complex MBMS pyrograms, but specific high-intensity peaks associated with individual compounds or compound classes can be identified, including acetic acid and hydroxyacetaldehyde $(\mathrm{m} / \mathrm{z}=60)$, carbohydrate fragments $(\mathrm{m} / \mathrm{z}=43,55,57$, and 73$)$, guaiacol $(\mathrm{m} / \mathrm{z}$ $=124)$, methylguaiacol $(\mathrm{m} / \mathrm{z}=138)$, 4-vinylguaiacol $(\mathrm{m} / \mathrm{z}=150)$, eugenol $(\mathrm{m} / \mathrm{z}=164)$, and coniferyl alcohol $(\mathrm{m} / \mathrm{z}=180) .{ }^{35}$ The MBMS pyrograms of non-catalyzed pine are in close agreement to previously reported results for fast pyrolysis of pine wood. ${ }^{21,25}$ When mixed-metal oxides were employed, the number of products was reduced, especially for heavy compounds ( $\mathrm{m} / \mathrm{z}$ $>115)$. In the catalyzed mass pyrograms, the major peaks observed include low-molecular-weight and non-condensable compounds such as water $(\mathrm{m} / \mathrm{z}=18)$, carbon monoxide $(\mathrm{m} / \mathrm{z}=28)$, and carbon dioxide $(\mathrm{m} / \mathrm{z}=44)$, as well as furan $(\mathrm{m} / \mathrm{z}=68)$, and aromatic compounds $(\mathrm{m} / \mathrm{z}=78,91$, and 106). 


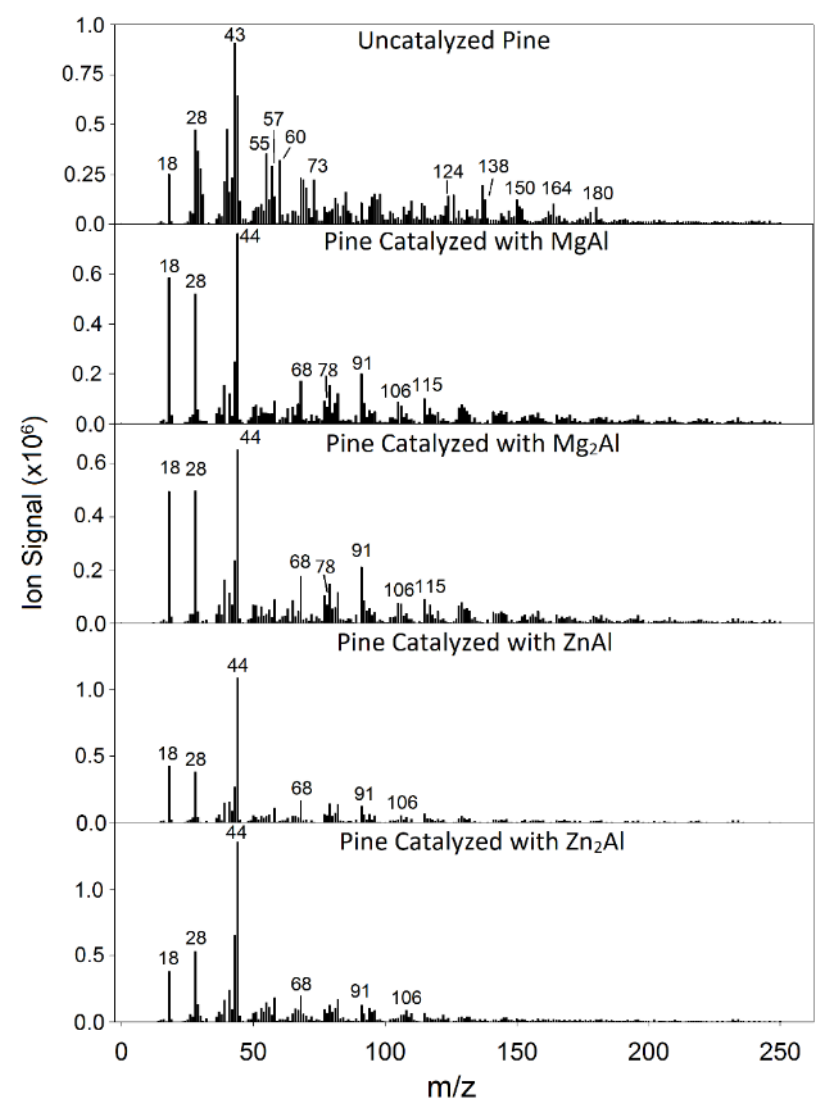

Figure 1. Pyrograms from the horizontal py-MBMS reactor of the non-catalyzed pine feedstock, and pine feedstock catalyzed with $\mathrm{MgAl}, \mathrm{Mg}_{2} \mathrm{Al}, \mathrm{ZnAl}$, and $\mathrm{Zn}_{2} \mathrm{Al}$ mixed-metal oxides with $\mathrm{B} / \mathrm{C}$ $=0.1$.

We used PCA to distinguish changes in the pyrolysis product-slate when different mixed-metal oxides were tested (Fig. 2). The pyrograms of four sequential biomass samples (50 mg) for each catalyst were analyzed. Data from the first run was removed as an outlier, due to initial changes to the catalyst, and boats 2-5 were used for the PCA. The PCA scores plot provides a visual representation of the similarities or differences in the vapor-phase products as determined by their placement along the principal component (PC) axes. The loadings plot indicates which major $\mathrm{m} / \mathrm{z}$ peaks are responsible for the variation between samples groups on the scores plot for each respective PC. Since the pyrograms were mean normalized, the obtained results communicate the relative proportions of the vapor products and should not be interpreted in terms of absolute yield. 
The PC1 scores plot accounts for $69 \%$ of the variation in the MBMS dataset and shows separation of the non-catalyzed and catalyzed samples mainly driven by low-molecular weight gases, water, $\mathrm{CO}$, and $\mathrm{CO}_{2}$ represented by $\mathrm{m} / \mathrm{z}$ of 18,28 , and 44 , respectively (Fig. 2). Thus, CFP with these mixed-metal oxides affords low-molecular weight gases. Removal of oxygen in the form of $\mathrm{H}_{2} \mathrm{O}, \mathrm{CO}$, or $\mathrm{CO}_{2}$ has been previously reported for CFP with metal oxides catalysts and indicates deoxygenation reactions such as decarbonylation, decarboxylation, ketonization, and dehydration. ${ }^{6,10,13,36}$

Catalyzed reactions result in more furans and aromatic compounds as evidenced by the positive fragments related to furan, methyl furan, toluene, and xylene $(\mathrm{m} / \mathrm{z}=68,82,91$, and $=106$, respectively). Pyrolysis vapors from the uncatalyzed reactions are consistent with raw pine. There is a trend of decreasing PC1 score with sequential sample introduction into the pyrolysis reactor, and this is more apparent in the $\mathrm{Zn}-\mathrm{Al}$ catalyzed systems (Fig. 2a). This indicates that the vapor composition is approaching that of the raw pine products because the catalysts are losing activity, and that the $\mathrm{Zn}-\mathrm{Al}$ materials are losing activity more quickly than the $\mathrm{Mg}-\mathrm{Al}$ materials.
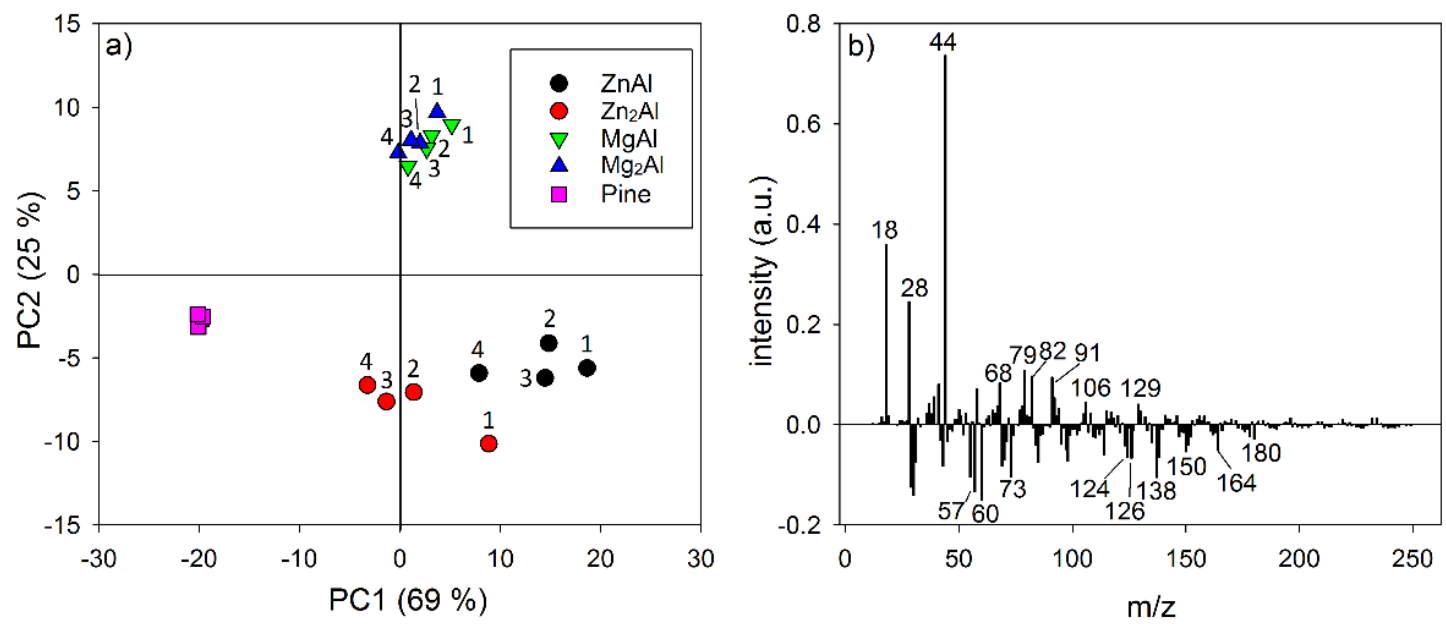

Figure 2. Principal component analysis of MBMS pyrograms from catalyzed and non-catalyzed pine feedstock showing a) the scores plot of PC1 vs. PC2 and b) the loadings plot for PC1. Each 
point in the scores plot represents one MBMS pyrogram from 4 successive $50 \mathrm{mg}$ biomass samples fed in the horizontal pyrolysis reactor with $\mathrm{B} / \mathrm{C}=0.1-0.25$.

To obtain greater discrimination between the pyrolysis products from the different catalysts, we performed a subsequent PCA excluding the non-catalyzed pine samples (Fig. 3). PC1 shows the separation of CFP products evolved from the $\mathrm{Mg}-\mathrm{Al}$ and $\mathrm{Zn}-\mathrm{Al}$ materials. The $\mathrm{Mg}-\mathrm{Al}$ materials group together on the negative portion of the $\mathrm{PC} 1$ axis, indicating that they form similar products. The loadings plot for $\mathrm{PC} 1$ shows that the $\mathrm{Zn}-\mathrm{Al}$ materials produced more $\mathrm{CO}_{2}(\mathrm{~m} / \mathrm{z}=44)$, with smaller positive contributions from acetone $(\mathrm{m} / \mathrm{z}=58)$ and methylfuran $(\mathrm{m} / \mathrm{z}=82)$. Increased $\mathrm{CO}_{2}$ release indicates that $\mathrm{Zn}-\mathrm{Al}$ materials promote decarboxylation reactions, and based on the $\mathrm{PC1}$ loadings, ketonization of acetic acid to form acetone and $\mathrm{CO}_{2}$ is likely occurring. In addition, $\mathrm{PC} 1$ shows that $\mathrm{Mg}-\mathrm{Al}$ catalysts produce more $\mathrm{H}_{2} \mathrm{O}(\mathrm{m} / \mathrm{z}=18)$ and $\mathrm{CO}(\mathrm{m} / \mathrm{z}=28)$ and more nonoxygenated aromatics, toluene and xylene $(\mathrm{m} / \mathrm{z}=91$ and 105 , respectively), compared to $\mathrm{Zn}-\mathrm{Al}$ materials (Fig. 3b). High oxygen content has been shown to reduce bio-oil stability and is a major challenge for fast pyrolysis technology. ${ }^{3-4}$ The greater proportion of deoxygenated aromatics afforded by the Mg-Al catalysts, compared to $\mathrm{Zn}-\mathrm{Al}$ catalysts, could be beneficial for bio-oil stability and down-stream processing.

PC2 of the scores plot shows rapid deactivation of $\mathrm{Zn}-\mathrm{Al}$ materials as indicated by the trend of more positive PC2 scores values as additional biomass samples are pyrolyzed and the fact that the positive loadings for PC2 show similarities to uncatalyzed pine (Fig. 3a). The PC2 loadings peaks that are common with uncatalyzed pine pyrolysis vapors include carbohydrate fragments $(\mathrm{m} / \mathrm{z}=$ 43 and 55), guaiacol $(\mathrm{m} / \mathrm{z}=124)$, methylguaiacol $(\mathrm{m} / \mathrm{z}=138)$, 4 -vinylguaiacol $(\mathrm{m} / \mathrm{z}=150)$, and eugenol $(\mathrm{m} / \mathrm{z}=164)($ Fig. 3c). While we are unable to unambiguously determine the reason for differences in reactivity, we hypothesize that it is related to differences in surface area and 
acidobasicity among the $\mathrm{Mg}-\mathrm{Al}$ and $\mathrm{Zn}-\mathrm{Al}$ mixed-metal oxides, as is discussed further in subsequent sections.
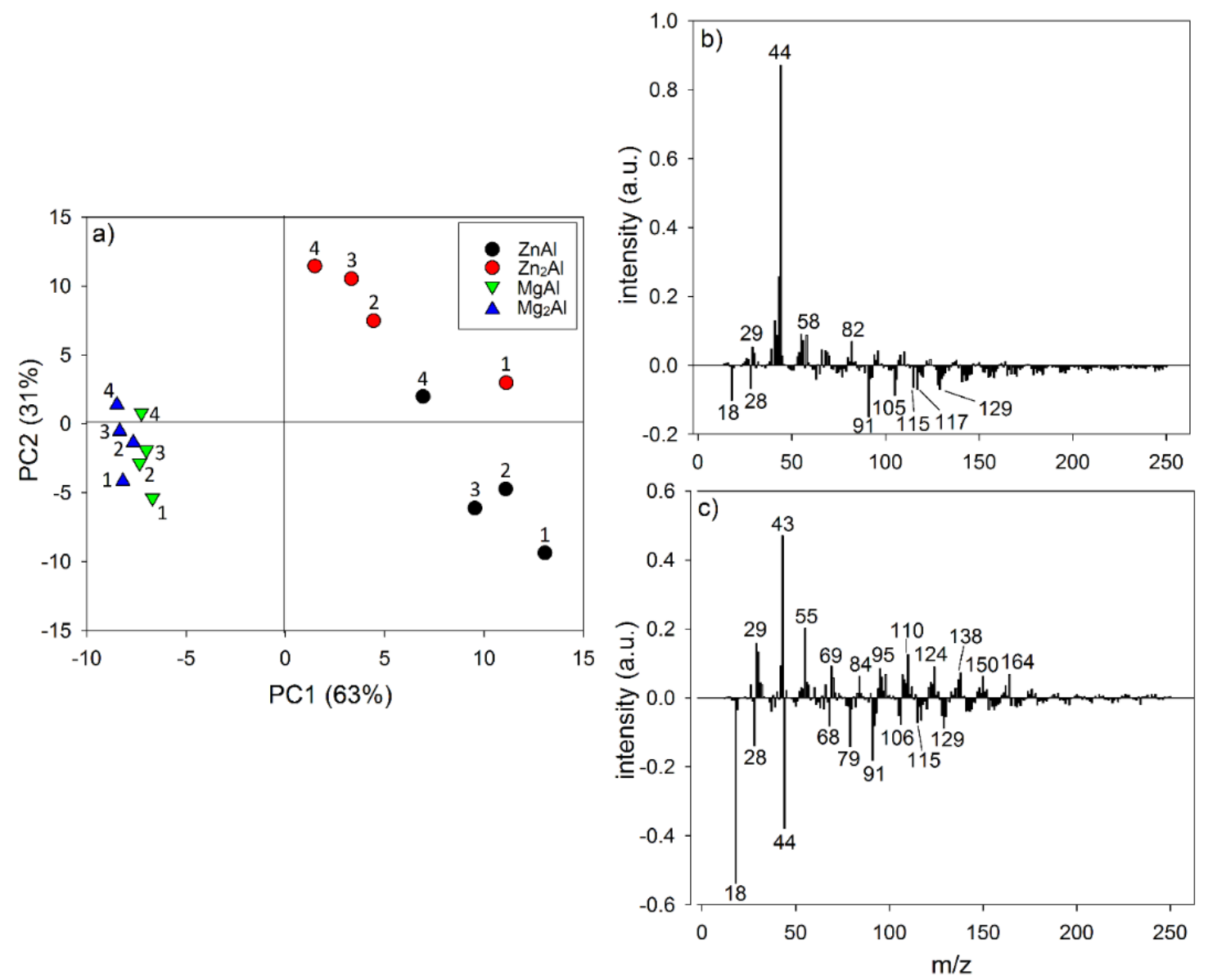

Figure 3. Principal component analysis of MBMS spectra from pine catalyzed by mixed-metal oxides; showing a) the scores plot of PC1 vs. PC2, b) the loadings plot for PC1, and c) the loadings plot for PC2. Each point in the scores plot represents one MBMS spectrum from 4 successive 50 $\mathrm{mg}$ biomass samples fed in the horizontal pyrolysis reactor with $\mathrm{B} / \mathrm{C}=0.1-0.25$.

We performed a comparison of peak areas of the major pyrolysis products measured during CFP of pine with mixed-metal oxide catalysts. Percent yields were calculated by summing the following normalized MBMS peaks over $250 \mathrm{mg}$ of biomass ( 5 boats) for each of the product categories as follows: water $(\mathrm{m} / \mathrm{z}=18), \mathrm{CO}(\mathrm{m} / \mathrm{z}=28), \mathrm{CO}_{2}(\mathrm{~m} / \mathrm{z}=44)$, acetic acid $(\mathrm{m} / \mathrm{z}=60)$, furans $(\mathrm{m} / \mathrm{z}=$ 
$68,82,96)$, simple phenols $(\mathrm{m} / \mathrm{z}=94,108,122,158)$, methoxyphenols $(\mathrm{m} / \mathrm{z}=124,137,150,152$, 164), total phenols (simple phenols + methoxyphenols), and aromatics ( $\mathrm{m} / \mathrm{z}=78,91,92,105$, and 106) (Fig. 4).

When mixed-metal oxide catalysts were employed, the proportion of acetic acid, methoxyphenols, and total phenols was substantially decreased, while aromatics and light gases $\left(\mathrm{H}_{2} \mathrm{O}, \mathrm{CO}\right.$, and $\left.\mathrm{CO}_{2}\right)$ increased compared to the non-catalyzed control (Fig. 4). The Zn-Al materials show greater $\mathrm{CO}_{2}$ production compared to the $\mathrm{Mg}$-Al catalysts, indicating that $\mathrm{Zn}-\mathrm{Al}$ materials are more active for decarboxylation reactions. The relative yield of deoxygenated aromatics is the highest when using the Mg-Al materials. These results are supported by the PCA discussed previously (Figs 2 and 3). In addition, there is a reduction in the total ion count when the catalysts are used, which is likely caused by coke deposition on the catalyst surface and a redistribution of the molecular weight of the pyrolysis products.

We are able to make preliminary comparisons between the product selectivity and deactivation behavior between these mixed-metal oxides and more traditional zeolites such as HZSM-5. Zeolite catalysts have been shown to be effective for upgrading lignocellulosic biomass pyrolysis vapors and show high selectivity towards hydrocarbon production. For example, HZSM-5 has been demonstrated to produce olefins, aromatic hydrocarbons, and gases $\left(\mathrm{H}_{2} \mathrm{O}, \mathrm{CO}\right.$, and $\left.\mathrm{CO}_{2}\right)$ when exposed to pine pyrolysis vapors, and similar to the mixed-metal oxide catalysts, a variety of products are formed after initial deactivation occurs. In general, coking and subsequent catalyst fouling are problematic during CFP with zeolites. ${ }^{37} \mathrm{We}$ will discuss these and additional conclusions in detail in the subsequent sections. 


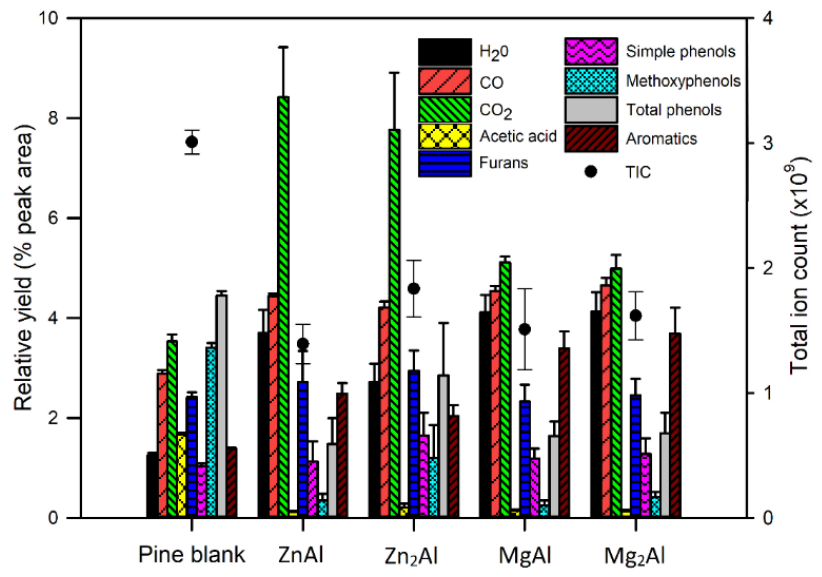

Figure 4. Vapor-phase pyrolysis product yields for pine feedstock without (pine blank) and with $\mathrm{ZnAl}, \mathrm{Zn}_{2} \mathrm{Al}, \mathrm{MgAl}$, and $\mathrm{Mg}_{2} \mathrm{Al}$ mixed-metal oxide catalysts. Vapor products were quantified by integrating and summing the peaks of interest, and then normalizing by the total pyrogram area. The relative yield is plotted on the left y-axis and total ion count is plotted on the right y-axis.

Catalyst Deactivation Behavior. Multivariate curve resolution (MCR) has previously been demonstrated as an effective tool to study catalyst deactivation behavior. ${ }^{21-22,}{ }^{24-25} \mathrm{MCR}$ is a statistical technique in which the "principal components" (PCs) are decomposed from the original MBMS spectra. Each PC represents a uniform mixture of compounds. The concentration of the mixture of compounds over the course of increasing $\mathrm{B} / \mathrm{C}$ is represented by the $\mathrm{PC}$ curve intensity in the component scores plot, while the composition of this mixture is represented by the loadings plot for each respective PC. The MCR plots show how the pyrolysis product slate is changing as $\mathrm{B} / \mathrm{C}$ increases. $\mathrm{B} / \mathrm{C}$ is determined as the addition of successive $50 \mathrm{mg}$ biomass samples which were pyrolyzed and their vapors passed through the $1 \mathrm{~g}$ catalyst bed.

Figure 5 shows the MCR for CFP of pine with $\mathrm{ZnAl}$ and illustrates the compositional evolution of the vapor-phase pyrolysis products as the catalyst undergoes deactivation. The red curve represents the initial products occurring during the initial biomass pulses and includes intense peaks for propylene $(\mathrm{m} / \mathrm{z}=41)$, acetone $(\mathrm{m} / \mathrm{z}=58)$, furan $(\mathrm{m} / \mathrm{z}=68)$, methylfuran $(\mathrm{m} / \mathrm{z}=82)$, 
benzene $(\mathrm{m} / \mathrm{z}=78)$, and toluene $(\mathrm{m} / \mathrm{z}=91)$. The signal at $\mathrm{m} / \mathrm{z} 115$ could be due to indene or naphthol fragmentation. ${ }^{38}$ The intermediate products (black curve) reach a maximum at $\mathrm{B} / \mathrm{C}=$ 0.45 , and the component loadings plot shows that this PC represents partially deoxygenated species, such as acetone $(\mathrm{m} / \mathrm{z}=58)$, furans and phenols including methylfuran $(\mathrm{m} / \mathrm{z}=82)$, phenol $(\mathrm{m} / \mathrm{z}=94)$, dimethyl furan or methylcyclopentenone $(\mathrm{m} / \mathrm{z}=96)$, methylphenol $(\mathrm{m} / \mathrm{z}=108)$, dimethylphenol $(\mathrm{m} / \mathrm{z}=122)$, trimethyl phenol $(\mathrm{m} / \mathrm{z}=136)$, and dimethylbenzofuran $(\mathrm{m} / \mathrm{z}=146)$. The primary vapors (blue curve) appear at a $\mathrm{B} / \mathrm{C}$ higher than 0.4 and they dominate at $\mathrm{B} / \mathrm{C}>1$, indicating that the catalyst was deactivated. The mass spectrum for the blue curve is similar to that for non-catalyzed pine in Figure 1. For comparison, the primary vapors breakthrough immediately for $\mathrm{Zn}_{2} \mathrm{Al}$, which indicates a relative lack of catalytic activity (Fig S3).
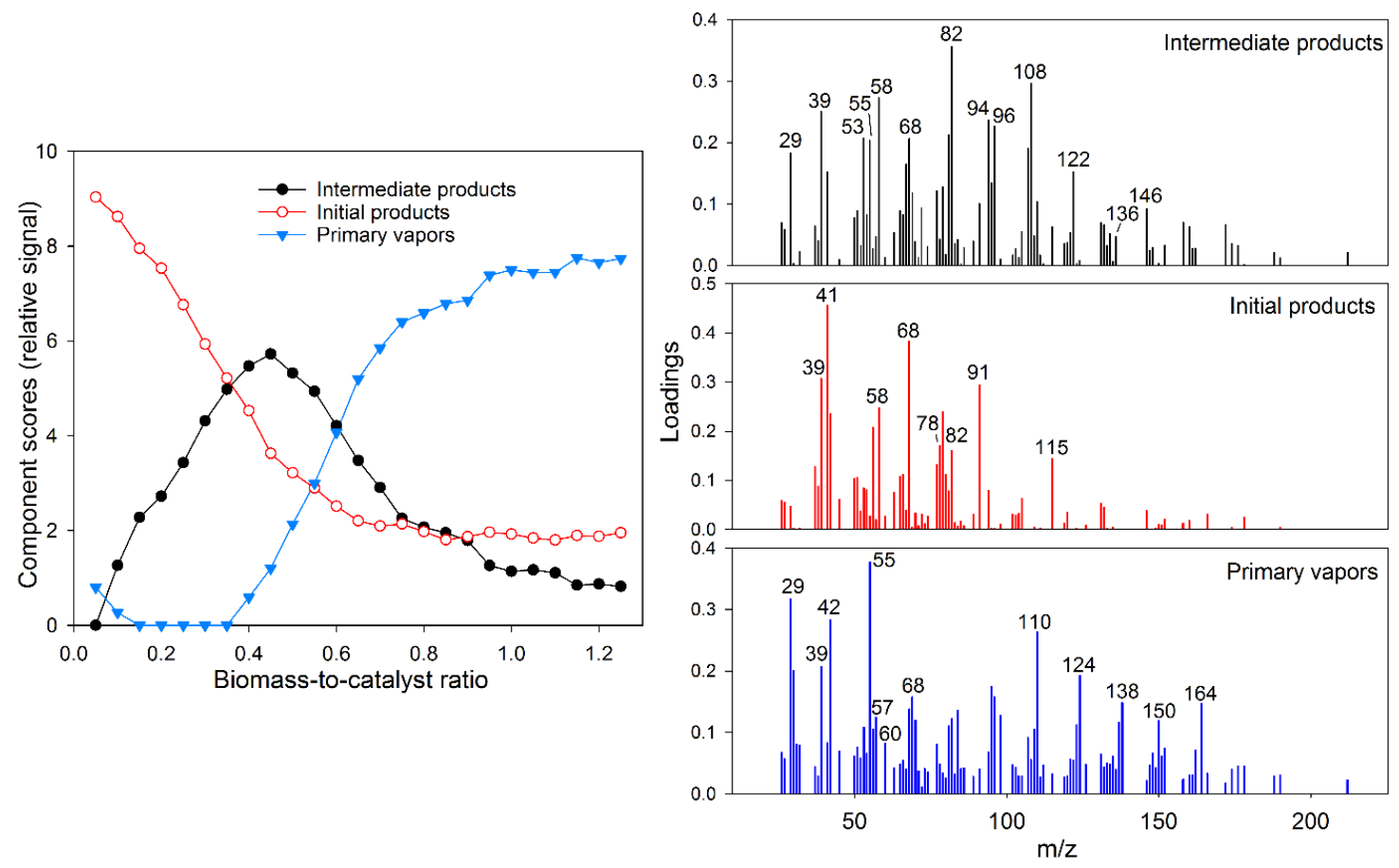

Figure 5. Multivariate curve resolution for ZnAl-catalyzed pine pyrolysis vapor products with respect to increasing $\mathrm{B} / \mathrm{C}$. The principal components scores (left) and accompanying loadings plots (right) are shown. 
The vapor-phase pyrolysis product slate for $\mathrm{Mg}_{2} \mathrm{Al}$ and $\mathrm{MgAl}$ are similar (Figs 6 and S4). The initial products show some compounds in common with $\mathrm{ZnAl}$, consisting of propylene $(\mathrm{m} / \mathrm{z}=41)$, furan $(\mathrm{m} / \mathrm{z}=39,42$, and 68$)$, methylfuran $(\mathrm{m} / \mathrm{z}=82)$, and toluene $(\mathrm{m} / \mathrm{z}=91)$. In addition, the initial products curve for $\mathrm{Mg}-\mathrm{Al}$ catalysts contained significant contributions from $\mathrm{xylene}(\mathrm{m} / \mathrm{z}=$ 106). In agreement with both the PCA and comparative product yield analysis, MCR shows that in the initial product vapors, the $\mathrm{Mg}$-Al catalysts produce greater proportions of deoxygenated aromatics such as toluene and xylene. The intermediate products curves for $\mathrm{MgAl}$ and $\mathrm{Mg}_{2} \mathrm{Al}$ consisted mostly of dimethyl furan, phenol, and methlyphenols. In the Mg-Al materials, the intermediate products reach a maximum at a higher $\mathrm{B} / \mathrm{C}=0.55$, compared to 0.45 in $\mathrm{ZnAl}$. In addition, the $\mathrm{B} / \mathrm{C}$ in which the primary vapor maximum occurs is highest in $\mathrm{Mg}_{2} \mathrm{Al}$ at 1.2 , indicating slightly prolonged activity compared to MgAl. Compared to HZSM-5, these mixedmetal oxides underwent deactivation slightly more quickly. For example, using HZSM-5 under similar conditions, Mukarakate and coworkers reported that the primary vapors breakthrough at a $\mathrm{B} / \mathrm{C}$ of 0.5 , intermediate products peaked at 0.8 , and the initial hydrocarbon products reached a minimum around $\mathrm{B} / \mathrm{C}$ of $1.6 .^{21}$ 

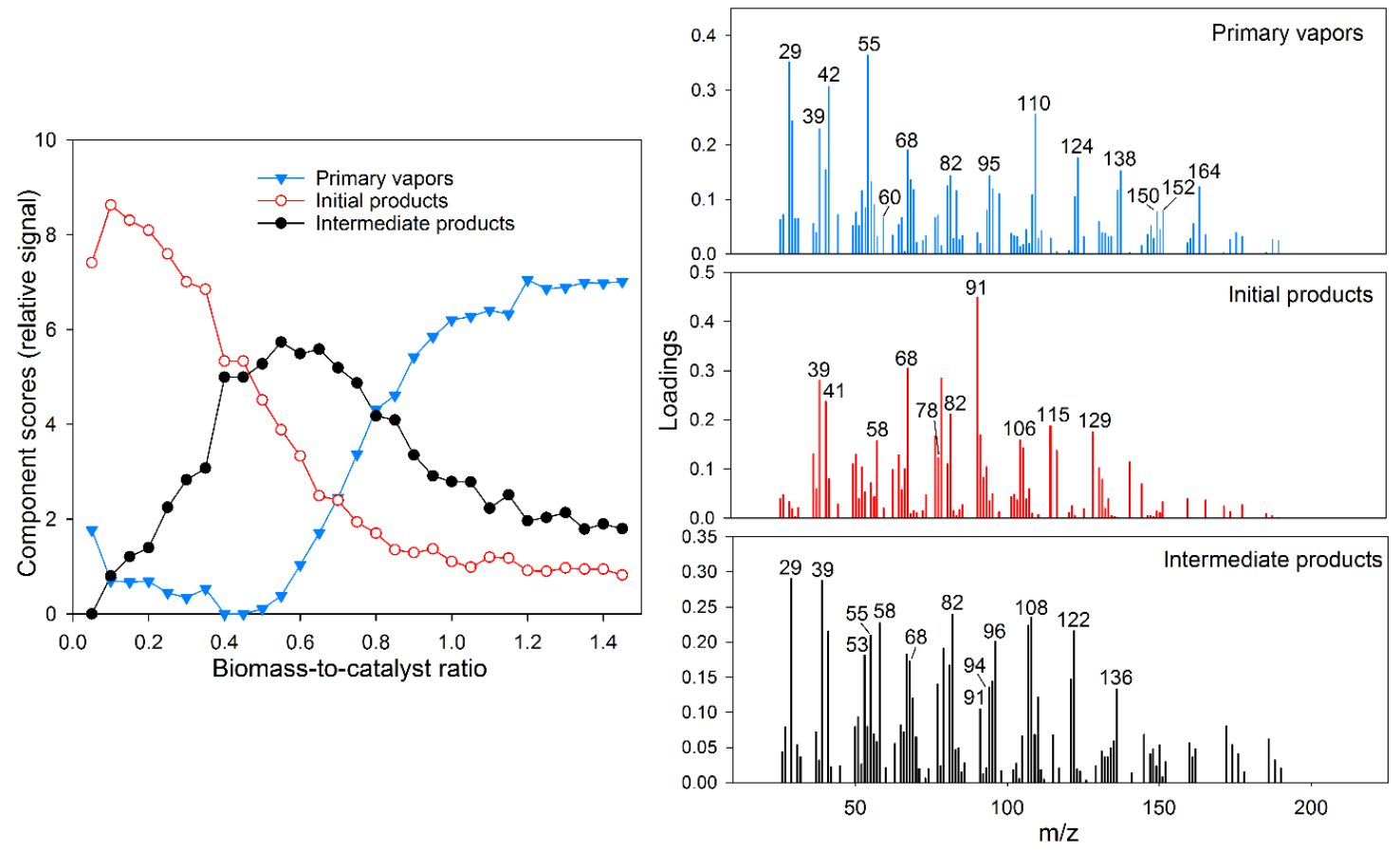

Figure 6. Multivariate curve resolution for $\mathrm{Mg}_{2} \mathrm{Al}$-catalyzed pine pyrolysis vapor products with respect to increasing $\mathrm{B} / \mathrm{C}$. The principal components scores (left) and accompanying loadings plots (right) are shown.

We performed XRD analysis on the deactivated catalyst samples, as shown in Figure S1. Overall, there is no indication of structural changes in the catalysts during or after deactivation. The peak positions and shapes stay relatively constant, suggesting that deactivation was likely a result of coke accumulation physically blocking catalytic active sites and not due to a change in the bulk structure of the materials.

We used TGA to measure the amount of coke accumulated on the catalysts at varying B/C. The TGA curves show minor weight loss caused by moisture and weakly adsorbed organic compounds at temperatures below $250{ }^{\circ} \mathrm{C}$, while weight loss occurring above $250{ }^{\circ} \mathrm{C}$ was attributed to combustion of coke. ${ }^{38}$ Hence, the weight loss in the range of $250{ }^{\circ} \mathrm{C}$ to $900{ }^{\circ} \mathrm{C}$ was used to determine the amount of coke accumulated on the catalysts (Table 2; Figure S5). 
As expected, there is a positive trend between $\mathrm{B} / \mathrm{C}$ and coke accumulation. $\mathrm{Zn} 2 \mathrm{Al}$ had less coke accumulation compared to the other catalysts. This may be related to its low surface area, and thus active sites were quickly blocked by coke even at low B/C. The Mg-Al materials showed greater coke accumulation and coke yields in the initial and intermediate phases of activity, which may be related to their higher surface area and greater quantity of active sites (especially in the case of $\mathrm{Mg}_{2} \mathrm{Al}$ ) which supported higher coke loadings before deactivation occurred.

Catalyst deactivation through coke deposition has widely been reported for metal oxides as well as microporous catalysts. ${ }^{6}$ For example, under similar reaction conditions with HZSM-5, Mukarakate et al. reported a coke yield of $15.5 \%$ (wt. coke/wt. biomass fed) after complete deactivation. ${ }^{21}$ For comparison, the mixed-metal oxides tested here (with the exception of $\mathrm{Zn}_{2} \mathrm{Al}$ ) showed similar coke yields after complete deactivation, ranging from 14.2-14.7\%.

Table 2. Coke accumulation at different stages of catalyst deactivation.

\begin{tabular}{ccccc}
\hline Catalyst & Activity $^{a}$ & Coke accumulation $^{b}$ & Coke yield $^{c}$ & Coke per basic site $^{d}$ \\
\hline \multirow{2}{*}{$\mathrm{ZnAl}$} & Initial (0.25) & 7.1 & 6.1 & 1.4 \\
& Intermediate (0.5) & 10.3 & 9.2 & 2.1 \\
& Deactivated (1.25) & 15.1 & 14.2 & 3.2 \\
\hline \multirow{2}{*}{$\mathrm{Zn}_{2} \mathrm{Al}$} & Initial (0.25) & 4.7 & 4.7 & 0.7 \\
& Intermediate (0.5) & 5.4 & 5.4 & 0.8 \\
& Deactivated (1.05) & 9.2 & 9.6 & 1.4 \\
\hline \multirow{2}{*}{$\mathrm{MgAl}$} & Initial (0.25) & 8.9 & 8.1 & 0.6 \\
& Intermediate (0.7) & 14.5 & 14.1 & 1.0 \\
& Deactivated (1.2) & 14.7 & 14.4 & 1.0 \\
\hline \multirow{2}{*}{$\mathrm{Mg}$ Al } & Intermediate (0.75) & 15.2 & 7.2 & 2.0 \\
& Initial (0.25) & 17.6 & 12.4 & 2.3 \\
\hline
\end{tabular}

$a \mathrm{~B} / \mathrm{C}$ given in parentheses 
$b$ Given as $\%$ by weight of coke versus catalyst

$c$ Given as $\%$ by weight of coke versus total fed biomass

$d$ Given as mg coke versus $\mu$ mol $\mathrm{CO}_{2}$ desorbed

Discussion of Catalyst Performance Descriptors. Understanding the effects of the mixed-metal oxide catalyst formulation on catalytic behavior is important to facilitate the design of improved catalysts. We observed that the identity of the divalent cation $\left(\mathrm{Mg}^{2+}\right.$ or $\left.\mathrm{Zn}^{2+}\right)$ affected the surface area and catalytic behavior of the reported materials. This is perhaps unsurprising, given the work of Kaguna and coworkers, who demonstrated that Zn-containing mixed-metal oxide materials displayed overall lower basicity than their Mg-containing counterparts. ${ }^{32}$

We were also able to observe an effect imparted by atom stoichiometries. For instance, in the Mg-Al materials, we observed an increase in basic site density and basic site strength when the divalent/trivalent cation ratio was changed from 2 to 1 (i.e., $\mathrm{Mg}_{2} \mathrm{Al}$ vs. $\mathrm{MgAl}$ ). However, despite these apparent differences in surface properties, $\mathrm{Mg}_{2} \mathrm{Al}$ and $\mathrm{MgAl}$ exhibited similar catalytic activity and deactivation behavior.

There is evidently an interplay between surface basicity (imparted by $\mathrm{MgO}$ and $\mathrm{ZnO}$ ) and Lewis acidity (imparted by $\mathrm{Al}_{2} \mathrm{O}_{3}$ ) among these materials, since the $\mathrm{Mg}$ - $\mathrm{Al}$ catalysts produce higher relative yields of non-oxygenated aromatics including toluene and xylene while remaining active at higher $\mathrm{B} / \mathrm{C}$ compared to $\mathrm{Zn}-\mathrm{Al}$ catalysts. The presence of amorphous alumina in the catalyst materials may explain the formation of non-oxygenated aromatics, which is reactivity typically ascribed to Lewis-acidic materials. Several preparations of mixed-metal oxides from layered double hydroxide precursors have previously shown no evidence for the presence crystalline alumina phases ${ }^{32}$ which is a finding similar to our own previous work. ${ }^{13}$ Furthermore, formation of $\gamma$-alumina from amorphous alumina has been shown to occur at $840{ }^{\circ} \mathrm{C},{ }^{39}$ which is well above the synthesis and calcination temperatures we employ here. This apparent acid-catalyzed reactivity 
highlights an area for improvement among these catalyst materials, since crystalline alumina phases are known to be more acidic (and therefore perhaps more catalytically active for the formation of non-oxygenated aromatics) than amorphous alumina. ${ }^{32,39-40}$

Given that deoxygenation and reduction of acidity of bio-oil are primary goals of catalytic upgrading and result in increased bio-oil stability, the results we report here are promising. However, the mixture of active sites on the surfaces of these mixed-metal oxides is complex and makes their characterization challenging. Our results demonstrate a mixture of weak, moderate, and strong basic sites, which we attribute to the presence of crystalline divalent metal oxides. Moreover, we infer the presence of moderately weak acidic sites which we attribute to the presence of amorphous alumina. Materials having several surface active sites that mediate multiple catalytic transformations simultaneously highlight some of the challenges inherit to designing, scaling, and deploying catalysts for thermochemical biomass conversion. Experiments to rigorously characterize these and other surface sites and their reactivities are ongoing in our laboratories.

\section{ASSOCIATED CONTENT}

The following files are available free of charge:

Compositional analysis of pine feedstock, additional multivariate curve resolutions of catalyst materials, powder x-ray diffractograms of freshly-prepared and after CFP experiments, $\mathrm{CO}_{2}$-TPD curves, and TGA weight loss curves.

\section{AUTHOR INFORMATION}

\section{Corresponding Authors}

*Email: nlabbe@utk.edu, schmely@utk.edu

\section{Author Contributions}


The manuscript was written through contributions of all authors.

\section{ACKNOWLEDGMENT}

This work was performed under the DOE-funded "Logistics for Enhanced-Attribute Feedstocks" (LEAF) Project, and this material is based upon work supported by the Department of Energy, Office of Energy Efficiency and Renewable Energy (EERE), under Award Number DEEE0006639. N.L. and S.C.C. also acknowledge support from the USDA National Institute of Food and Agriculture, Hatch Project 1012359. In addition, this work was authored in part by Alliance for Sustainable Energy, LLC, the manager and operator of the National Renewable Energy Laboratory for the U.S. Department of Energy (DOE) under Contract No. DE-AC36-08GO28308. Funding provided by U.S. Department of Energy Office of Energy Efficiency and Renewable Energy Bioenergy Technologies Office. The views expressed in the article do not necessarily represent the views of the DOE or the U.S. Government. The U.S. Government retains and the publisher, by accepting the article for publication, acknowledges that the U.S. Government retains a nonexclusive, paid-up, irrevocable, worldwide license to publish or reproduce the published form of this work, or allow others to do so, for U.S. Government purposes.

\section{REFERENCES}

1. Mohan, D.; Pittman, C. U.; Steele, P. H., Pyrolysis of Wood/Biomass for Bio-oil: A Critical Review. Energy Fuels 2006, 20 (3), 848-889. DOI: 10.1021/ef0502397

2. Bridgwater, A. V., Renewable Fuels and Chemicals by Thermal Processing of Biomass. Chem. Eng. J. 2003, 91 (2-3), 87-102. DOI: 10.1016/s1385-8947(02)00142-0

3. Carpenter, D.; Westover, T. L.; Czernik, S.; Jablonski, W., Biomass Feedstocks for Renewable Fuel Production: A Review of the Impacts of Feedstock and Pretreatment on the Yield 
and Product Distribution of Fast Pyrolysis Bio-Oils and Vapors. Green Chem. 2014, 16 (2), 384406. DOI: $10.1039 / \mathrm{c} 3 g c 41631 \mathrm{c}$

4. Ruddy, D. A.; Schaidle, J. A.; Ferrell Iii, J. R.; Wang, J.; Moens, L.; Hensley, J. E., Recent Advances in Heterogeneous Catalysts for Bio-Oil Upgrading via "Ex Situ Catalytic Fast Pyrolysis": Catalyst Development through the Study of Model Compounds. Green Chem. 2014, 16 (2), 454-490. DOI: $10.1039 / \mathrm{c} 3 \mathrm{gc} 41354 \mathrm{c}$

5. Wan, S.; Wang, Y., A Review on Ex Situ Catalytic Fast Pyrolysis of Biomass. Front. Chem. Sci. Eng. 2014, 8 (3), 280-294. DOI: 10.1007/s11705-014-1436-8

6. Liu, C.; Wang, H.; Karim, A. M.; Sun, J.; Wang, Y., Catalytic Fast Pyrolysis of Lignocellulosic Biomass. Chem. Soc. Rev. 2014, 43 (22), 7594-7623. DOI: 10.1039/c3cs60414d

7. Guda, V. K.; Toghiani, H., Catalytic Pyrolysis of Pinewood Using Metal Oxide Catalysts in an Integrated Reactor System. Biofuels 2016, 8 (5), 527-536. DOI: $10.1080 / 17597269.2016 .1231960$

8. Nguyen, T. S.; He, S.; Raman, G.; Seshan, K., Catalytic Hydro-Pyrolysis of Lignocellulosic Biomass Over Dual $\mathrm{Na}_{2} \mathrm{CO}_{3} / \mathrm{Al}_{2} \mathrm{O}_{3}$ and $\mathrm{Pt} / \mathrm{Al}_{2} \mathrm{O}_{3}$ Catalysts Using n-Butane at Ambient Pressure. Chem. Eng. J. 2016, 299, 415-419. DOI: 10.1016/j.cej.2016.04.104

9. Nguyen, T. S.; Zabeti, M.; Lefferts, L.; Brem, G.; Seshan, K., Conversion of Lignocellulosic Biomass to Green Fuel Oil over Sodium Based Catalysts. Bioresour. Technol. 2013, 142, 353-360. DOI: 10.1016/j.biortech.2013.05.023

10. Karnjanakom, S.; Guan, G.; Asep, B.; Du, X.; Hao, X.; Yang, J.; Samart, C.; Abudula, A., A Green Method to Increase Yield and Quality of Bio-Oil: Ultrasonic Pretreatment of Biomass 
and Catalytic Upgrading of Bio-Oil Over Metal (Cu, Fe and/ar $\mathrm{Zn}) / \gamma-\mathrm{Al}_{2} \mathrm{O}_{3} . R S C A d v .2015,5$ (101), 83494-83503. DOI: $10.1039 / \mathrm{c} 5 \mathrm{ra} 14609 \mathrm{~g}$

11. Karnjanakom, S.; Bayu, A.; Xiaoketi, P.; Hao, X.; Kongparakul, S.; Samart, C.; Abudula, A.; Guan, G., Selective Production of Aromatic Hydrocarbons from Catalytic Pyrolysis of Biomass over $\mathrm{Cu}$ or Fe Loaded Mesoporous Rod-Like Alumina. RSC Adv. 2016, 6 (56), 5061850629. DOI: $10.1039 / \mathrm{c} 6 \mathrm{ra} 09431 \mathrm{~g}$

12. Mante, O. D.; Rodriguez, J. A.; Senanayake, S. D.; Babu, S. P., Catalytic Conversion of Biomass Pyrolysis Vapors into Hydrocarbon Fuel Precursors. Green Chem. 2015, 17 (4), 23622368. DOI: $10.1039 / \mathrm{c} 4 \mathrm{gc} 02238 \mathrm{f}$

13. Kim, P.; Rials, T. G.; Labbé, N.; Chmely, S. C., Screening of Mixed-Metal Oxide Species for Catalytic Ex Situ Vapor-Phase Deoxygenation of Cellulose by py-GC/MS Coupled with Multivariate Analysis. Energy Fuels 2016, 30 (4), 3167-3174. DOI: 10.1021/acs.energyfuels.6b00347

14. Navarro, R. M.; Guil-Lopez, R.; Fierro, J. L. G.; Mota, N.; Jiménez, S.; Pizarro, P.; Coronado, J. M.; Serrano, D. P., Catalytic fast pyrolysis of biomass over Mg-Al mixed oxides derived from hydrotalcite-like precursors: Influence of Mg/Al ratio. J. Anal. Appl. Pyrolysis 2018, 134, 362-370. DOI: 10.1016/j.jaap.2018.07.001

15. Debecker, D. P.; Gaigneaux, E. M.; Busca, G., Exploring, Tuning, and Exploiting the Basicity of Hydrotalcites for Applications in Heterogeneous Catalysis. Chem. Eur. J. 2009, 15 (16), 3920-3935. DOI: 10.1002/chem.200900060 
16. Di Cosimo, J. I.; Díez, V. K.; Xu, M.; Iglesia, E.; Apesteguía, C. R., Structure and Surface and Catalytic Properties of Mg-Al Basic Oxides. J. Catal. 1998, 178 (2), 499-510. DOI: 10.1006/jcat.1998.2161

17. Sideris, P. J.; Nielsen, U. G.; Gan, Z.; Grey, C. P., Mg/Al Ordering in Layered Double Hydroxides Revealed by Multinuclear NMR Spectroscopy. Science 2008, 321 (5885), 113-117. DOI: $10.1126 /$ science. 1157581

18. Sluiter, A.; Hames, B.; Ruiz, R.; Scarlata, C.; Sluiter, J.; Templeton, D. Determination of Ash in Biomass; NREL/TP-510-42622; 2008.

19. Sluiter, A.; Hames, B.; Ruiz, R.; Scarlata, C.; Sluiter, J.; Templeton, D. Determination of Structural Carbohydrates and Lignin in Biomass: Laboratory Analytical Procedure (LAP); NREL/TP-510-42618; 2010.

20. Microwave Assisted Acid Digestion of Siliceous and Organically Based Matrices; US EPA Method 3052 rev. 0; 1996.

21. Mukarakate, C.; Zhang, X.; Stanton, A. R.; Robichaud, D. J.; Ciesielski, P. N.; Malhotra, K.; Donohoe, B. S.; Gjersing, E.; Evans, R. J.; Heroux, D. S.; Richards, R.; Iisa, K.; Nimlos, M. R., Real-Time Monitoring of the Deactivation of HZSM-5 During Upgrading of Pine Pyrolysis Vapors. Green Chem. 2014, 16 (3), 1444-1461. DOI: 10.1039/c3gc42065e

22. Budhi, S.; Mukarakate, C.; Iisa, K.; Pylypenko, S.; Ciesielski, P. N.; Yung, M. M.; Donohoe, B. S.; Katahira, R.; Nimlos, M. R.; Trewyn, B. G., Molybdenum Incorporated Mesoporous Silica Catalyst for Production of Biofuels and Value-Added Chemicals via Catalytic Fast Pyrolysis. Green Chem. 2015, 17 (5), 3035-3046. DOI: 10.1039/c4gc02477j 
23. Kim, P.; Weaver, S.; Labbé, N., Effect of Sweeping Gas Flow Rates on TemperatureControlled Multistage Condensation of Pyrolysis Vapors in an Auger Intermediate Pyrolysis System. J. Anal. Appl. Pyrolysis 2016, 118, 325-334. DOI: 10.1016/j.jaap.2016.02.017

24. Jia, L. Y.; Raad, M.; Hamieh, S.; Toufaily, J.; Hamieh, T.; Bettahar, M. M.; Mauviel, G.; Tarrighi, M.; Pinard, L.; Dufour, A., Catalytic Fast Pyrolysis of Biomass: Superior Selectivity of Hierarchical Zeolites to Aromatics. Green Chem. 2017, 19 (22), 5442-5459. DOI: $10.1039 / \mathrm{c} 7 \mathrm{gc} 02309 \mathrm{j}$

25. Mukarakate, C.; Watson, M. J.; ten Dam, J.; Baucherel, X.; Budhi, S.; Yung, M. M.; Ben, H.; Iisa, K.; Baldwin, R. M.; Nimlos, M. R., Upgrading Biomass Pyrolysis Vapors over $\beta$-Zeolites: Role of Silica-to-Alumina Ratio. Green Chem. 2014, 16 (12), 4891-4905. DOI: $10.1039 / \mathrm{c} 4 \mathrm{gc} 01425 \mathrm{a}$

26. Murugappan, K.; Mukarakate, C.; Budhi, S.; Shetty, M.; Nimlos, M. R.; Román-Leshkov, Y., Supported molybdenum oxides as effective catalysts for the catalytic fast pyrolysis of lignocellulosic biomass. Green Chem. 2016, 18 (20), 5548-5557. DOI: 10.1039/c6gc01189f

27. U.S. Department of Energy. 2016. 2016 Billion-Ton Report: Advancing Domestic Resources for a Thriving Bioeconomy, Volume 1: Economic Availability of Feedstocks. M. H. Langholtz, B. J. Stokes, and L. M. Eaton (Leads), ORNL/TM-2016/160. Oak Ridge National Laboratory, Oak Ridge, TN. 448p. doi: 10.2172/1271651. http://energy.gov/eere/bioenergy/2016billion-ton-report

28. Abelló, S.; Medina, F.; Tichit, D.; Pérez-Ramírez, J.; Groen, J. C.; Sueiras, J. E.; Salagre, P.; Cesteros, Y., Aldol Condensations Over Reconstructed Mg-Al Hydrotalcites: Structure- 
Activity Relationships Related to the Rehydration Method. Chem. Eur. J. 2005, 11 (2), 728-739. DOI: $10.1002 /$ chem.200400409

29. Zhang, Z. B.; Lu, Q.; Ye, X. N.; Li, W. T.; Hu, B.; Dong, C. Q., Selective Analytical Production of 1-Hydroxy-3,6-dioxabicyclo[3.2.1]octan-2-one from Catalytic Fast Pyrolysis of Cellulose with Zinc-Aluminium Layered Double Oxide Catalyst. Bioresources 2015, 10 (4), 8295 8311. DOI:

30. Béres, A.; Pálinkó, I.; Kiricsi, I., Synthesis of Layered Double Hydroxides and Their Reactivities in 1-Butene Isomerization after Calcination. React. Kinet. Catal. Lett. 1996, 59 (1), 47-52. DOI: 10.1007/bf02067991

31. Pérez-Barrado, E.; Pujol, M. C.; Aguiló, M.; Llorca, J.; Cesteros, Y.; Díaz, F.; Pallarès, J.; Marsal, L. F.; Salagre, P., Influence of Acid-Base Properties of Calcined MgAl and CaAl Layered Double Hydroxides on the Catalytic Glycerol Etherification to Short-chain Polyglycerols. Chem. Eng. J. 2015, 264, 547-556. DOI: 10.1016/j.cej.2014.11.117

32. Kagunya, W.; Hassan, Z.; Jones, W., Catalytic Properties of Layered Double Hydroxides and Their Calcined Derivatives. Inorg Chem 1996, 35 (21), 5970-5974. DOI: 10.1021/ic960047e

33. Climent, M. J.; Corma, A.; Iborra, S.; Primo, J., Base Catalysis for Fine Chemicals Production: Claisen-Schmidt Condensation on Zeolites and Hydrotalcites for the Production of Chalcones and Flavanones of Pharmaceutical Interest. J. Catal. 1995, 151 (1), 60-66. DOI: 10.1006/jcat. 1995.1008

34. Corma, A.; Iborra, S.; Miquel, S.; Primo, J., Catalysts for the Production of Fine Chemicals. J. Catal. 1998, 173 (2), 315-321. DOI: 10.1006/jcat.1997.1930 
35. Evans, R. J.; Milne, T. A., Molecular Characterization of the Pyrolysis of Biomass. Energy Fuels 1987, 1 (2), 123-137. DOI: 10.1021/ef00002a001

36. Stefanidis, S. D.; Kalogiannis, K. G.; Iliopoulou, E. F.; Lappas, A. A.; Pilavachi, P. A., InSitu Upgrading of Biomass Pyrolysis Vapors: Catalyst Screening on a Fixed Bed Reactor. Bioresour. Technol. 2011, 102 (17), 8261-8267. DOI: 10.1016/j.biortech.2011.06.032

37. Dickerson, T.; Soria, J., Catalytic Fast Pyrolysis: A Review. Energies 2013, 6 (1), 514538. DOI: $10.3390 / \mathrm{en} 6010514$

38. Mukarakate, C.; McBrayer, J. D.; Evans, T. J.; Budhi, S.; Robichaud, D. J.; Iisa, K.; ten Dam, J.; Watson, M. J.; Baldwin, R. M.; Nimlos, M. R., Catalytic Fast Pyrolysis of Biomass: The Reactions of Water and Aromatic Intermediates Produces Phenols. Green Chem. 2015, 17 (8), 4217-4227. DOI: $10.1039 / \mathrm{c} 5 \mathrm{gc} 00805 \mathrm{k}$

39. Abbattista, F.; Delmastro, S.; Gozzelino, G.; Mazza, D.; Vallino, M.; Busca, G.; Lorenzelli, V.; Ramis, G., Surface Characterization of Amorphous Alumina and Its Crystallization Products. J. Catal. 1989, 117 (1), 42-51. DOI: 10.1016/0021-9517(89)90219-4

40. Nortier, P.; Fourre, P.; Saad, A. B. M.; Saur, O.; Lavalley, J. C., Effects of Crystallinity and Morphology on the Surface-Properties of Alumina. Appl Catal 1990, 61 (1), 141-160. DOI: $10.1016 / \mathrm{S} 0166-9834(00) 82140-5$ 
Supporting information

\section{Vapor-phase Stabilization of Biomass Pyrolysis Vapors Using Mixed-metal Oxide Catalysts}

Charles W. Edmunds ${ }^{1}$, Calvin Mukarakate ${ }^{2}$, Mengze $\mathrm{Xu}^{2}$, Yagya N. Regmi ${ }^{1}$, Choo Hamilton ${ }^{1}$, Joshua A. Schaidle ${ }^{2}$, Nicole Labbé ${ }^{1 *}$, Stephen C. Chmely ${ }^{1 *}$

1. Center for Renewable Carbon, The University of Tennessee Institute of Agriculture, 2506 Jacob Drive, Knoxville, Tennessee 37996, USA

2. National Renewable Energy Laboratory, 15013 Denver West Parkway, Golden, Colorado 80401 USA

Corresponding authors' email: nlabbe@utk.edu, schmely@utk.edu

\section{Table of Contents}

Table S1. Compositional analysis of the pine feedstock

Page S-2

Figure S1. Powder x-ray diffraction patterns of catalysts

Page S-3

Figure S2. $\mathrm{CO}_{2}$ TPD curves of catalysts

Page S-4

Figure S3. Multivariate curve resolution for $\mathrm{Zn}_{2} \mathrm{Al}$

Page S-5

Figure S4. Multivariate curve resolution for MgAl

Page S-6

Figure S5. Representative TGA weight loss curve

Page S-7 
Table S1. Compositional analysis of the pine feedstock used for catalytic fast pyrolysis.

\begin{tabular}{lc}
\hline Component & Concentration \\
\hline Chemical composition (\% wt.) & $42.2(0.1)^{\mathrm{a}}$ \\
Cellulose & $19.3(0.0)$ \\
Hemicellulose & $32.9(0.4)$ \\
Lignin & $2.9(0.2)$ \\
Extractives & $0.6(0.1)$ \\
Ash & \\
\hline Ultimate analysis (\% wt.) & $49.7(0.1)$ \\
$\mathrm{C}$ & $6.2(0.2)$ \\
$\mathrm{H}$ & $0.1(0.0)$ \\
$\mathrm{N}$ & $43.4(0.2)$ \\
$\mathrm{O}$ & $399(5)$ \\
\hline Inorganic composition $(\mathrm{mg} / \mathrm{kg})$ \\
$\mathrm{K}$ & $1207(51)$ \\
$\mathrm{Ca}$ & $555(28)$ \\
$\mathrm{Mg}$ & $76(3)$ \\
$\mathrm{P}$ & $80(3)$ \\
$\mathrm{S}$ & $113(3)$ \\
$\mathrm{Fe}$ & $748(65)$ \\
$\mathrm{Si}$ & $81(3)$ \\
$\mathrm{Al}$ & $6(1)$ \\
$\mathrm{Na}$ &
\end{tabular}

aParentheses indicate standard deviation calculated from three replicates 

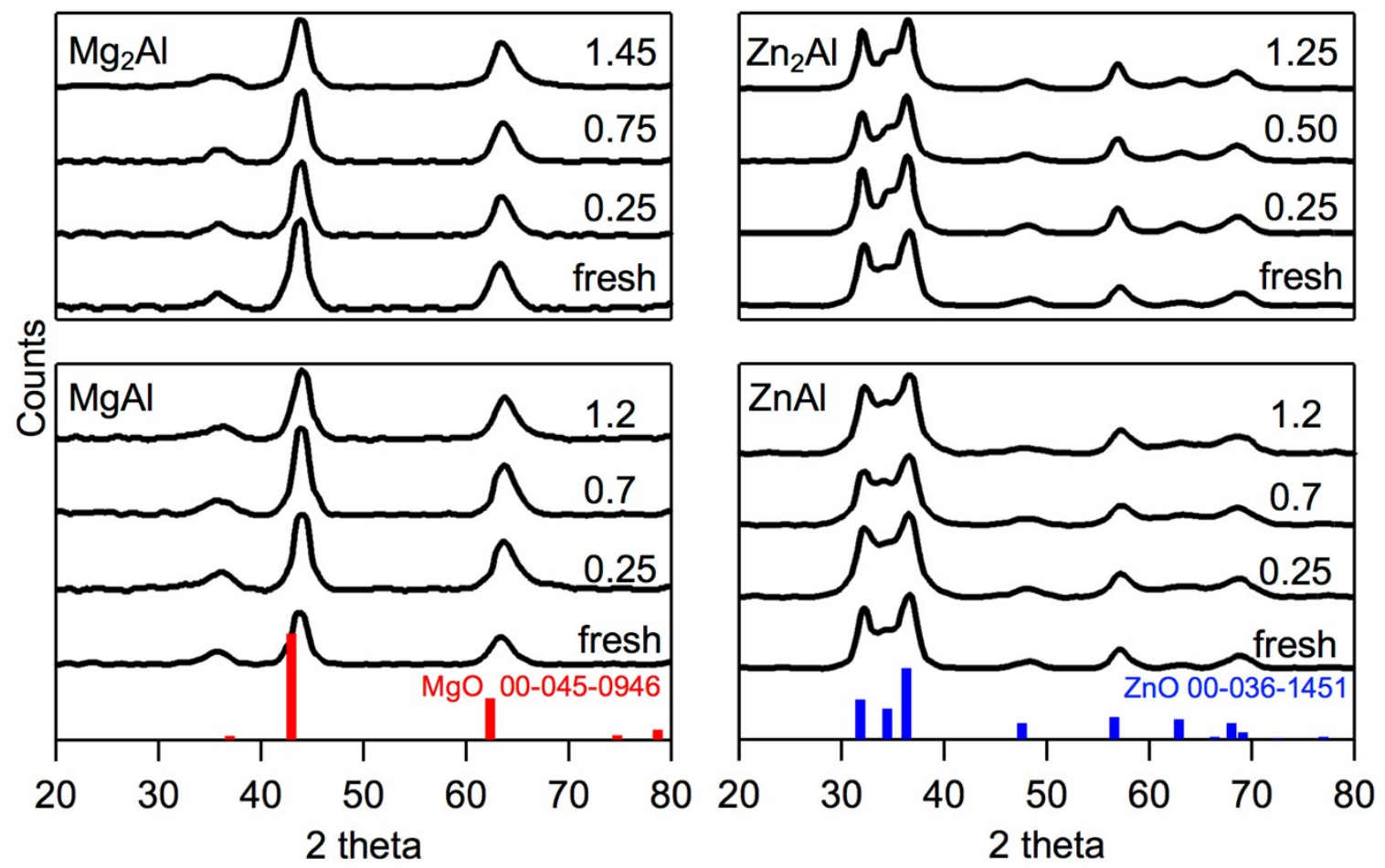

Figure S1. Powder x-ray diffraction patterns of $\mathrm{ZnAl}, \mathrm{Zn}_{2} \mathrm{Al}$, MgAl, and $\mathrm{Mg}_{2} \mathrm{Al}$ that are freshly prepared and after CFP experiments at several different biomass-to-catalyst ratios, along with reference patterns for $\mathrm{MgO}$ (00-045-0946) and $\mathrm{ZnO}(00-036-1451)$. 


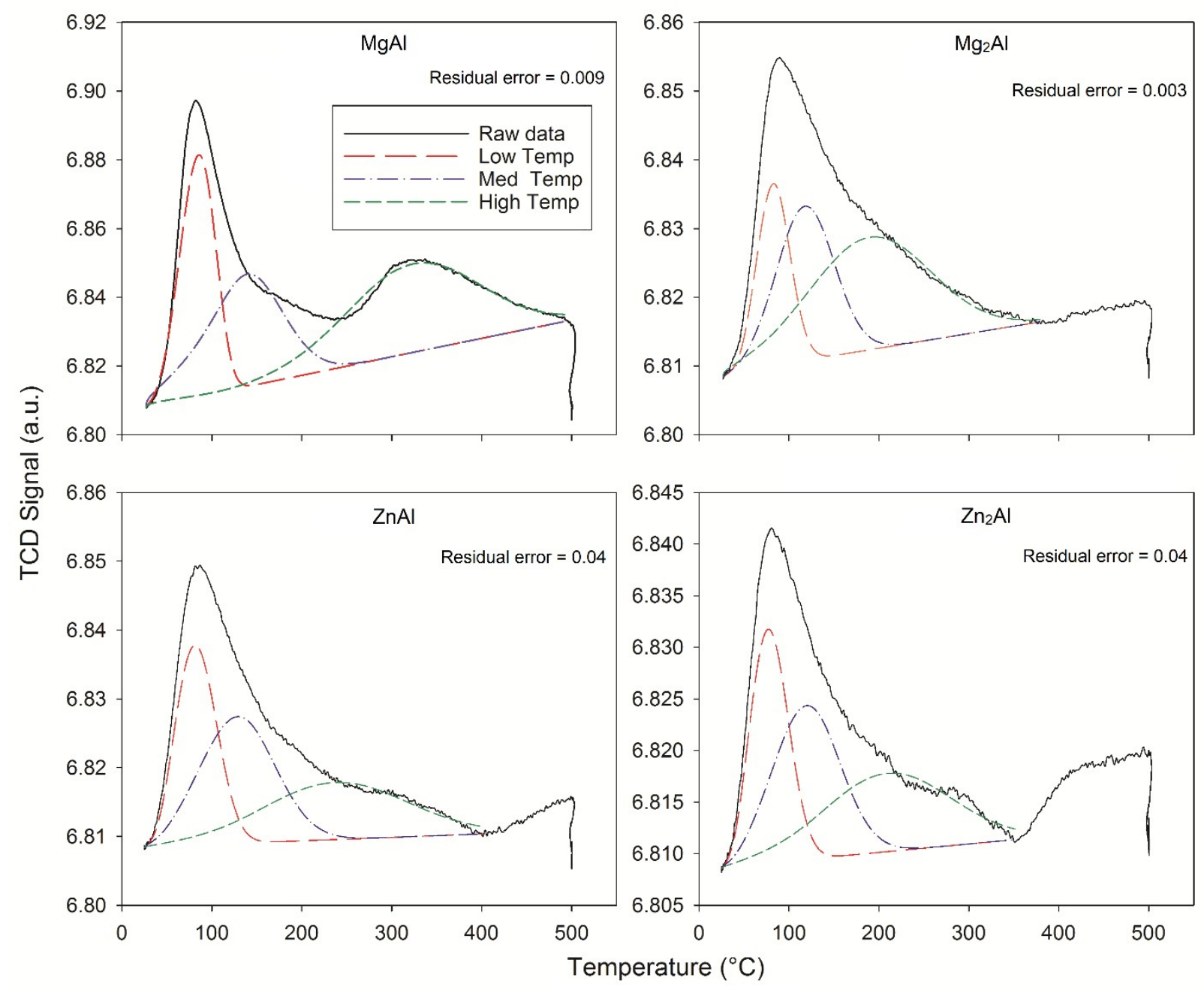

Figure S2. $\mathrm{CO}_{2}$ temperature programed desorption (TPD) curves of fresh $\mathrm{Mg}-\mathrm{Al}$ and $\mathrm{Zn}$ Al mixed metal oxide catalysts, the original data, the deconvoluted peaks (low, medium, and high peaks), and the residual error of the original and deconvoluted peaks are shown. 

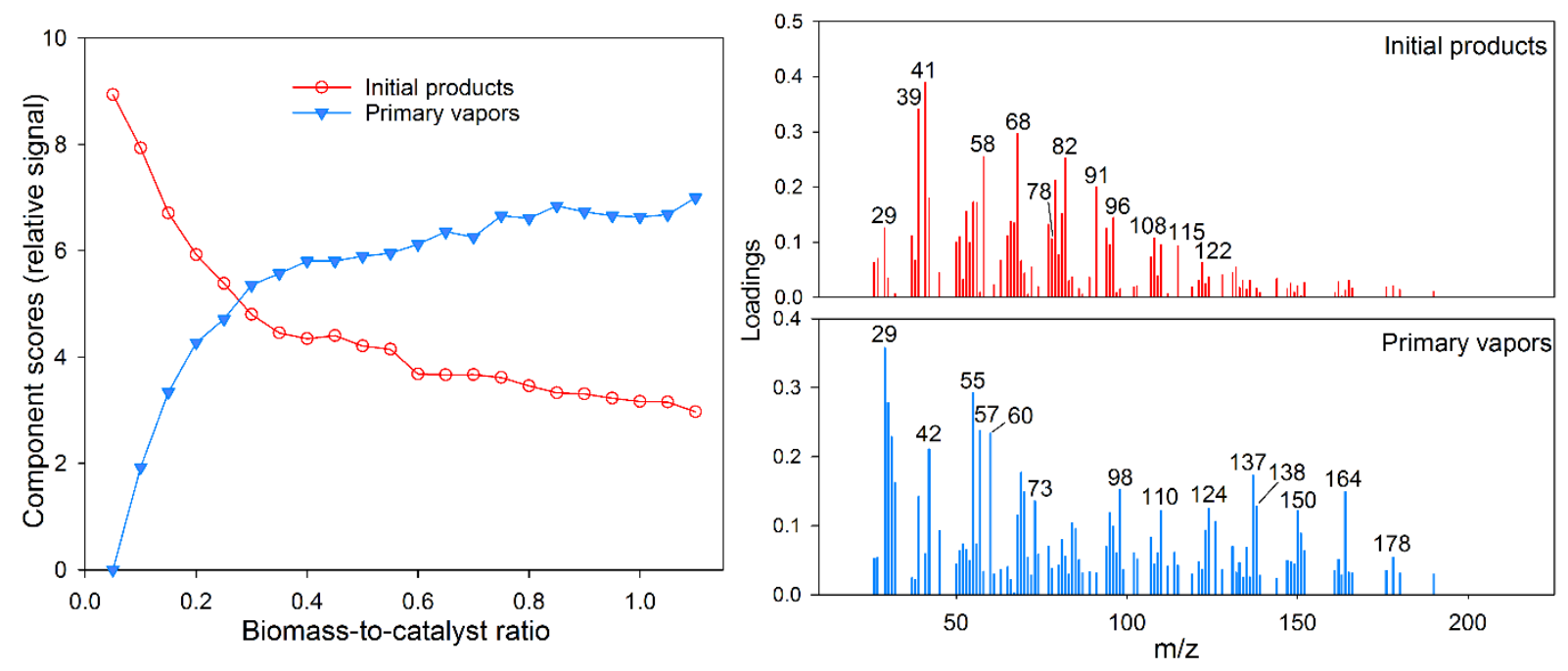

Figure S3. Multivariate curve resolution for $\mathrm{Zn}_{2} \mathrm{Al}$-catalyzed pine pyrolysis vapor products with respect to increasing biomass-to-catalyst ratio. The principal components scores (left) and accompanying loadings plots (right) are shown. 

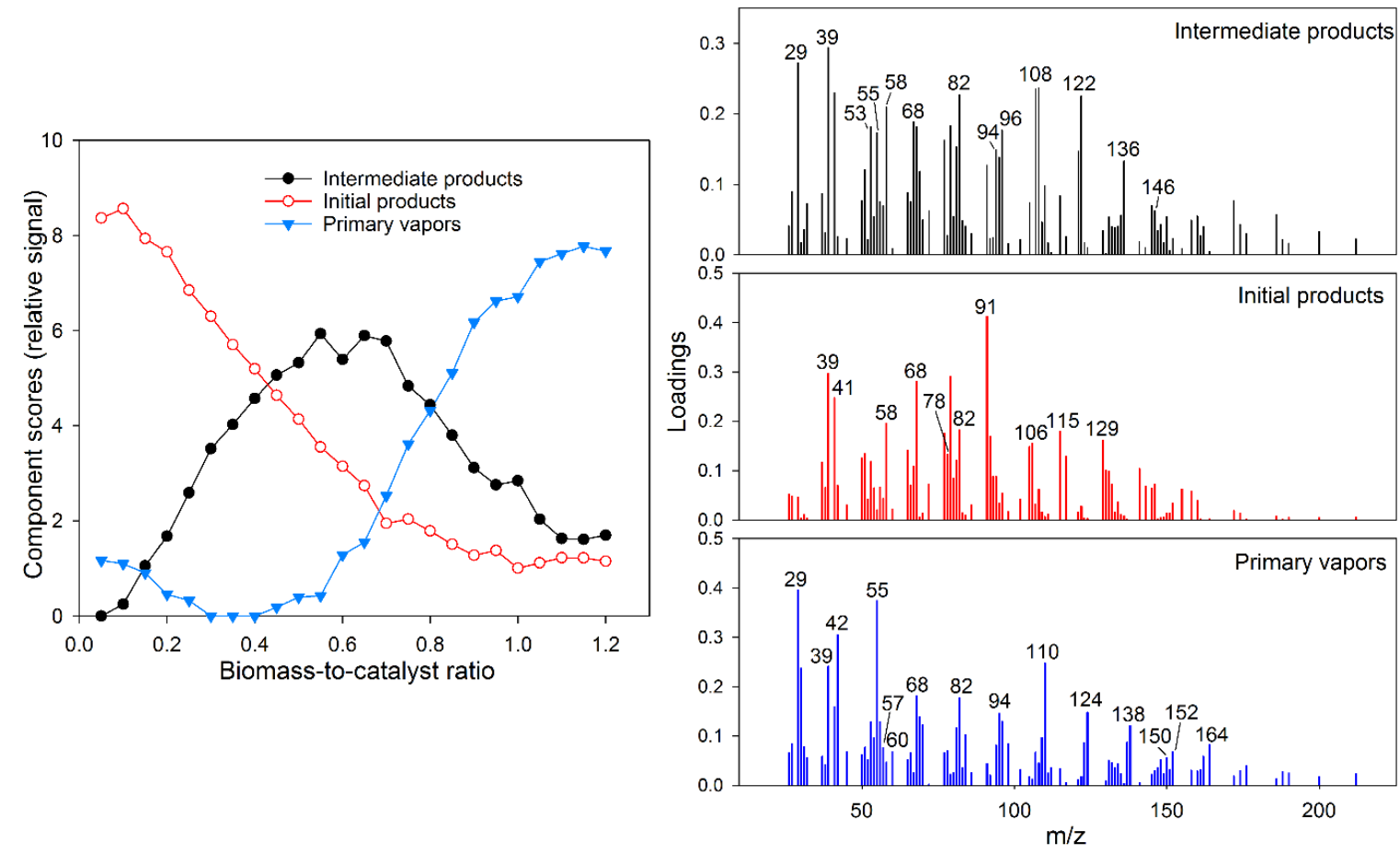

Figure S4. Multivariate curve resolution for MgAl-catalyzed pine pyrolysis vapor products with respect to increasing biomass-to-catalyst ratio. The principal components scores (left) and accompanying loadings plots (right) are shown. 


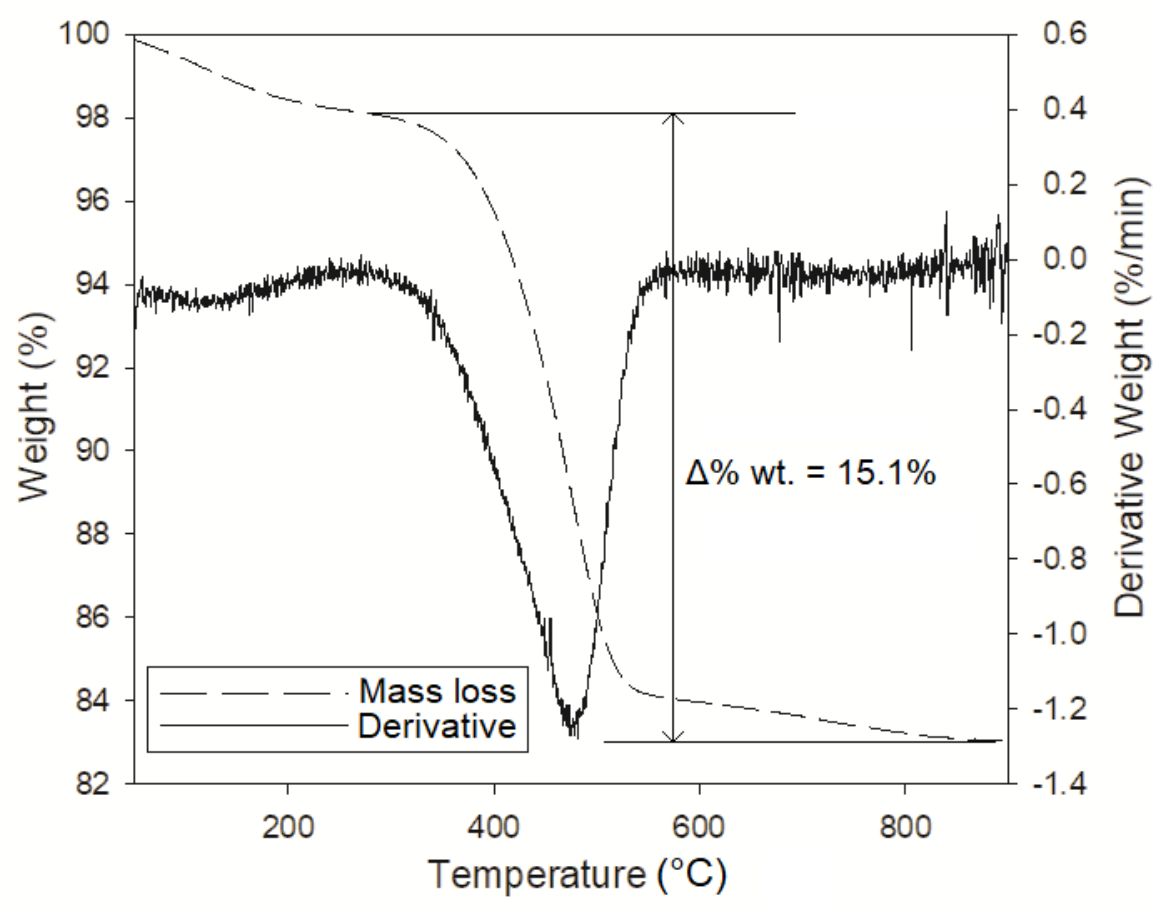

Figure S5. A representative TGA weight loss and derivate weight loss curve. Spent $\mathrm{ZnAl}$ catalyst is shown. 
